\title{
THE OLIVE TREE, A SOURCE OF ANTIOXIDANT COMPOUNDS
}

\section{Gabriella Tamasi,, Claudia Bonechi,, Anastasiya Belyakova, ${ }^{1}$ Alessio Pardini,1 Claudio Rossi ${ }^{1,2}$}

\author{
${ }^{1}$ Department of Biotechnologies, Chemistry and Pharmacy, University of Siena; \\ ${ }^{2}$ Operative Unit, University of Siena, CampoVerde, Calabria, Italy
}

\begin{abstract}
Products from Olea europaea L. i.e. leaves, olive oil and pomace are promising sources of bioactive compounds. In leaves, antioxidant compounds show a concentration dependence on the vegetative cycle of the trees, higher antioxidant concentration coinciding with seasonal vegetative changes. Olive oil, but particularly pomances are a rich source of health-giving effect compounds more specifically polyphenolic antioxidants. Many of these compounds may be of interest for pharmaceutical, cosmetic and food industry, especially because both pomance and leaves are currently considered waste of the olive oil production.
\end{abstract}

Key words: Antioxidant, olive tree, pomace, olive leaves, polyphenols, flavonoids, carotenoids.

\section{INTRODUCTION}

Olea europaea L.: diffusion, history and mythology

The olive tree is a fruit tree of the Oleaceae family, species Olea europaea L. Although it is one of the oldest and most widespread plants in the world, it is difficult to exactly pinpoint its origin as a cultivated plant. It is thought to have first been cultivated in ancient times by indigenous Middle Eastern people [1]. Probably native to Syria, between 4000 and $1400 \mathrm{BC}$, it spread to Egypt, Crete and Attica and thence to the rest of the Mediterranean with the help of the Phoenicians, Greeks and Carthaginians (Figure 1), where its cultivation was favoured by particularly suitable climate and soils [2,3].

Olive cultivation was developed by the Greeks, for whom the plant was of great importance. The utility of the olive in antiquity was so great that it was considered a gift of the gods. In Greek mythology, the first olive tree is attributed to the goddess Athena. In disputing the dominion of Attica, Poseidon and Athena vied to offer the people the greater gift. Poseidon used his trident to create a spring of seawater on land (another source has him creating the first horse, symbol of war and power), claiming that the Athenians would rule the waves. Athena used her lance to create the first olive tree: a gift of food, cosmetics, medicine and lighting. Faced with a choice between power and war or well-being and peace, the people preferred Athena's gift and the capital of Attica was named Athens in her honour. The tree, which sprang up on the Acropolis, was guarded by soldiers after being declared sacred and protector of the city.

The olive has been considered sacred by many peoples, presumably not only because of its virtues, but also because it is a hardy and long-living plant. The olive is considered an immortal tree due to its natural longevity. Its trunk can regenerate from the roots, enabling a tree to live for thousands of years [4].

In the Mediterranean area, a correlation is evident between cultivation of the olive and cultural development, since olive growing and oil production, symbols of a stable society, called for knowledge and agricultural technology. Until the middle of the seventh century BC, the Etruscans imported olive oil from Greece. Large quantities of oil were transported by sea in amphorae and small quantities for preparation of perfumed ointments were shipped in small vessels. The Etruscans subsequently learned olive cultivation and oil production from the Greeks.

In the second century $\mathrm{BC}$, olive cultivation spread to Magna Graecia, where the Romans became acquainted with it. The Romans brought olive cultivation and use of olive oil to all the lands they conquered [1]. The olive was a key element of Mediterranean culture, its oil being known as green gold. As a source of light it is a symbol of the great monotheistic religions. Olive oil was used to anoint Olympic athletes and is an essential in-

\section{Correspondence to:}

Claudio Rossi

Department of Biotechnologies, Chemistry and Pharmacy, University of Siena

Via Aldo Moro 2, 53100 Siena, Italy

Tel.: +39.0577.234355

E-mail: claudio.rossi@unisi.it 
gredient of the Mediterranean diet. Since antiquity it is valued for its health-giving properties and considered a product intermediate between food and medicine.

The fruits, oil and leaves of the olive tree, together with cereals, are major Mediterranean crops, bestowing economic and health benefits on the peoples of the region, where traditional therapeutic, dietetic and ceremonial uses handed down over thousands of years persist to the present day.

The olive has always been a symbol of abundance, glory and peace. Its fronds were used historically to crown victors of games and battles [5]. In the Bible, a white dove carrying an olive twig appears to Noah, announcing the end of the flood. The olive twig represents a new life and the promise of resurrection, as well as spiritual rebirth. Elsewhere in the Bible (Ezekiel 47, 12), the properties of the plant are mentioned: "Their leaves will not wither, nor will their fruit fail ... Their fruit will serve for food and their leaves for healing."

With the decline of the Roman Empire and the beginning of the barbaric invasions, olive cultivation diminished sharply and almost disappeared. The olive was cultivated almost exclusively in monasteries for religious needs and lighting. The Benedictine monks, whose motto was Ora et labora (Pray and work), persuaded the peasants not to abandon the land but to grow olive trees, and by the end of the Middle Ages olive cultivation had again reached high levels of production. Indeed, the congregation of the olivetani founded in 1313 at Monte Oliveto Maggiore (Siena Province) is Benedictine [4].

Today the olive tree is not limited to the Mediter- ranean basin, but is widely cultivated in different parts of the world, including South Africa, China, Vietnam and throughout the Americas.

\section{Olea europaea L.: brief botanical description}

The olive is an evergreen tree. Its vegetative phase continues throughout the year with a reduction in activity during Winter. As a native to the dry subtropical Mediterranean area, it adapts very well to extreme environmental and agricultural conditions, often living for centuries [6].

The root system is extensive and very superficial, consisting mainly of adventitious roots that spread laterally near the surface. The trunk has smooth greyishgreen bark until about the tenth year of age, after which it becomes knotty, contorted and furrowed with bark of a darker colour. Plants that have lived for centuries can become very tall and wide. The trunk gives rise to branches and fronds which carry the buds that produce annual growth [7].

The fruits of the olive tree are small oval drupes called olives. The olive tree is unique among the 600 species of Oleaceae as the only plant to have fruit that can be used directly for food (table olives) or after processing (olive oil). Fruiting takes place over a period of two years. The size of the ripe drupe varies with cultivar and growing conditions and does not exceed 2-3 $\mathrm{cm}$ in diameter. Fruits have a thin exocarp, a fleshy mesocarp consisting of parenchyma cells rich in oil (the quantity of which varies with cultivar and season) and a central woody endocarp. Olives are produced every second year through a phenomenon known as induc-

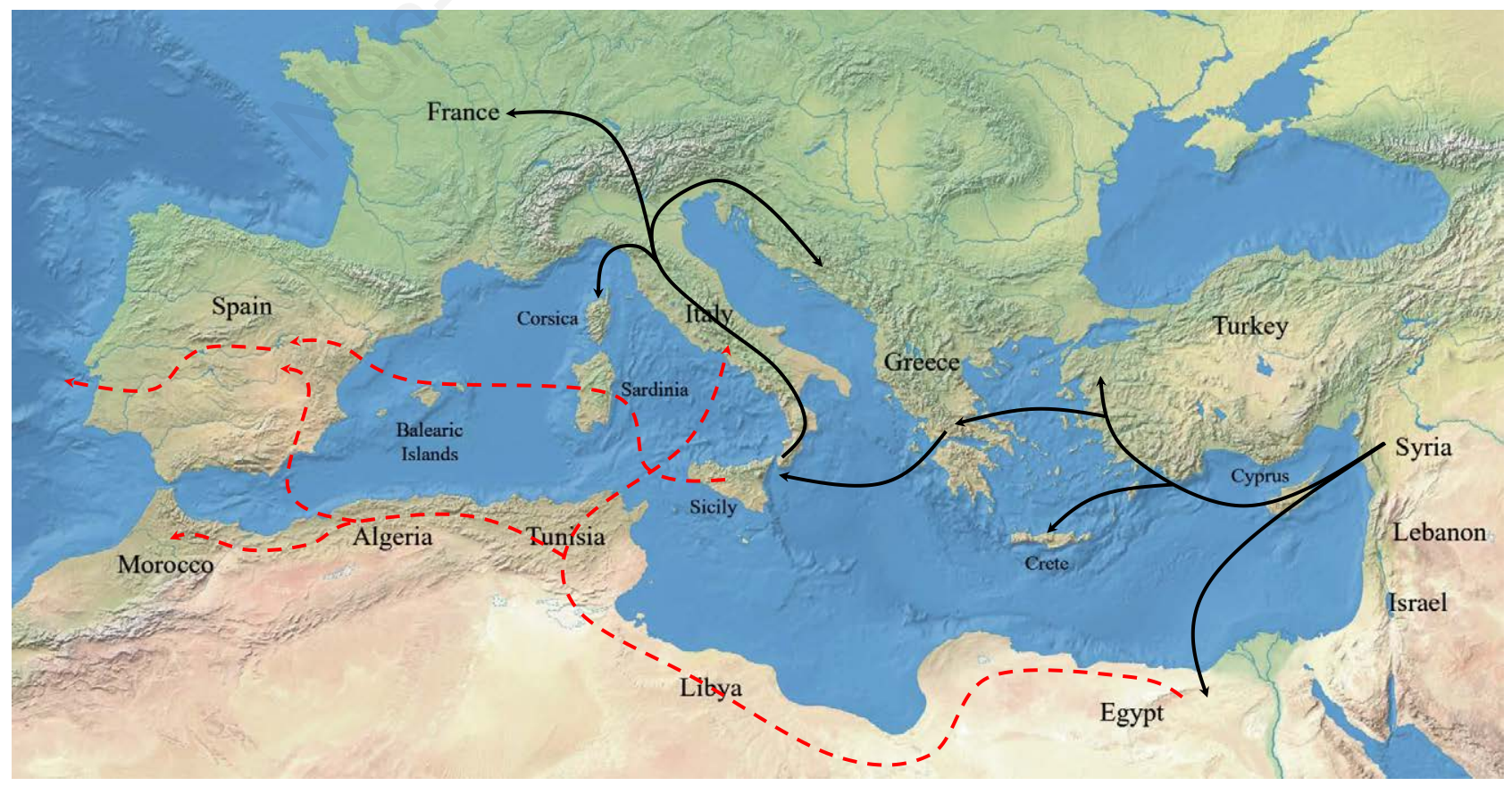

Figure 1. Diffusion of the olive tree in the Mediterranean basin. 
tion. Annual development and endogenous metabolic factors determine the transformation of undifferentiated tissue into vegetative and/or reproductive buds. In general, a year of low production is accompanied by high vegetative activity and vice versa [7].

Leaves grow from Spring to Autumn and are shed after two years. They are arranged in opposite distichous whorls and have entire margins. They are leathery, elliptic or lanceolate, variably dark green above, shiny due to waxes and opaque silvery-grey below. High sensitivity to light causes a large difference in photosynthesis between external and inner leaves, less exposed to light. Leaves are roughly flat and $30-80 \mathrm{~mm}$ long, but their dimension varies in a given cultivar in relation to age of plant, vigour of branch and phase of development in the span of a vegetative season: leaves that form shortly before Summer vegetative arrest tend to remain small $[7,8]$.

Trichomes, also known as pluricelluar leaf plaques can overlap to form 3-4 layers over stomata to protect them and induce stomal transpiration, which is more active on the underside of the leaf. Thus the function of layers with cuticle, that reduce water loss, is accentuated. Stellate hairs protect the mesophyll and stomata on the underside from UV radiation, especially in early phases of leaf development, and reduce the effects of wind. Limited intercellular spaces in palisade and spongy tissue resist diffusion of gases inside the leaf, confirming the xerophytic adaptation of olive trees. In dry years, trees spontaneously shed many of their leaves in order to reduce the surface area of transpiration and prevent wilting [8].

\section{Phenological cycle of the olive}

Phenology is generally described as the art of observing life cycle phases or activities of plants and animals in their temporal occurrence throughout the year [9]. Phenology is therefore concerned with evaluating growth rates in relation to different endogenous and exogenous factors, such as biorhythms, light and temperature.

Various phenological scales have been established for cultivated species. Although related, they do not necessarily coincide due to different aims, which may be botanical, agronomic, applications in general, each concerned with only certain phenological stages of the plants [10]. The $\mathrm{BBCH}$ (Biologische Bundesanstalt, Bundessortenamt, Chemische Industrie) [11] scale is officially recognised by the European Plant Protection Organization (EPPO) for the description of a wide range of vegetative stages of crops and wild plants. It is a decimal scale that can be used to describe monocots and dicots. It is divided into eight main development stages for buds, leaves and shoots and 32 secondary stages. As regards the olive, the phenological stages can be indicated as in Table 1. Figure 2 shows the development of olive trees during the growing season. Phenological growth stages are specific for each species, but the moment when each stage is reached differs between cultivars and years [12].

The phenological cycle of olive trees is very sensitive to weather conditions. Phenology is important for understanding how plants adapt to local climatic conditions and how they respond to changes, such as early onset of Spring or an extended Autumn [13].

\section{Olive products and by-products: oil, pomace and olive mill waste waters}

Cultivation of olive trees and olive oil production by pressing of ripe olives is an essential agricultural activity in the Mediterranean area. Olive oil production is a tradition, though improvements and automation have facilitated the processes.

The olives are washed to remove dirt, stones and other material adhering to the fruits. They are then crushed in hammer mills (milling) and the skins, pits and crushed pulp, known collectively as pomace, is churned (malaxation) to favour the separation of the water fraction from the oil, emulsified during milling [14]. This is followed by extraction that was traditionally performed by pressing. This method is relatively obsolete. Used for centuries with only minor modifications, today it is still practised by some oil producers. Pressing produces an emulsion containing olive oil, which is subsequently separated by decantation of the aqueous fraction. Pomace is the solid by-product of pressing. Several decades ago, two types of centrifuge, two-phase and three-phase (Figure 3), were intro-

\begin{tabular}{|c|c|c|c|c|c|c|c|c|c|c|c|c|}
\hline & January & February & March & April & May & June & July & August & September & October & November & December \\
\hline Ripening & & & & & & & & & & & & \\
\hline \begin{tabular}{|l|} 
Fruit \\
Development
\end{tabular} & & & & & & & & & & & & \\
\hline Flowering & & & & & & & & & & & & \\
\hline $\begin{array}{l}\text { Inflorescence } \\
\text { Development }\end{array}$ & & & & & & & & & & & & \\
\hline \begin{tabular}{|l|} 
Leaf \\
Development
\end{tabular} & & & & & & & & & & & & \\
\hline
\end{tabular}

Figure 2. Development of olive trees during the growing season (adapted from Sanz-Cortés et al., 2002) [12]. 
duced. The three-phase method produces three distinct fractions at the end of the process: a solid fraction (pomace) and two liquid fractions (oil and aqueous fraction, olive mill waste waters). The advantages with respect to pressing include complete automation and better oil quality; the disadvantages include higher consumption of water and energy, larger aqueous fraction and more expensive plant [15].

Possible uses for waste water and pomace (usually disposed of as waste) have recently been studied to reduce environmental impact [16]. Olive leaves are another by-product of olive oil production. Leaves

Table 1. Selected phenological stages of the olive tree on the basis of the BBCH scale.

\section{Principal growth stage 0: Bud development}

00 Foliar buds at the apex of shoots that developed the previous crop-year are completely closed, sharp-pointed, stemless and ochre-coloured.

01 Foliar buds start to swell and open, showing the new foliar primordia.

03 Foliar buds lengthen and separate from the base.

07 External small leaves open, not completely separated, remaining joined at the apices.

09 External small leaves open further with their tips inter-crossing.

\section{Principal growth stage 1: Leaf development}

11 First leaves completely separated. Greenish-grey colour.

15 The leaves are longer without reaching their final length. First leaves turn greenish on the upper side.

19 Leaves achieve the length and shape typical of the cultivar.

\section{Principal growth stage 3: Shoot development}

31 Shoots reach $10 \%$ of final length.

33 Shoots reach $30 \%$ of final length.

37 Shoots reach $70 \%$ of final length.

\section{Principal growth stage 5: Inflorescence emergence}

50 Inflorescence buds in leaf axils are completely closed. They are sharp-pointed, stemless and ochre-coloured.

51 Inflorescence buds start to swell.

53 Inflorescence buds open. Flower cluster development starts.

54 Flower clusters grow.

55 Flower clusters totally expanded. Floral buds start to open.

57 Corolla green-coloured, longer than calyx.

59 Corolla changes colour from green to white.

\section{Principal growth 6: Flowering}

60 First flowers open.

61 Beginning of flowering: $10 \%$ of flowers open.

65 Full flowering: at least $50 \%$ of flowers open

67 First petals falling.

68 Majority of petals fallen or wilted.

69 End of flowering, fruit set, non-fertilised ovaries fallen.

Principal growth stage 7: Fruit development

71 Fruit about $10 \%$ of final size.

75 Fruit about $50 \%$ of final size. Stone becomes lignified (shows resistance to cutting).

79 Fruit about $90 \%$ of final size. Fruit suitable for picking green.

\section{Principal growth stage 8: Maturity of fruit}

80 Fruit a deep green colour becoming light green or yellowish.

81 Beginning of fruit colouring.

85 Increasing specific fruit colouring.

89 Harvest maturity: fruit achieves the colour typical of the cultivar, remains turgid and is suitable for oil extraction 
constitute about $10 \%$ by weight of the olive crop and large quantities accumulate when olive trees are pruned [17].

\section{CHEMICAL CHARACTERISATION}

Olives and olive oil have been associated with humans and their traditions over thousands of years. They are an essential component of the Mediterranean diet. Consumed all over the world, their high content in monounsaturated fatty acids and phenols gives them an important nutritional role. They are also a major source of natural antioxidants, which besides protecting olives and olive oil against oxidation, are beneficial for human health, as in the prevention of coronary artery disease and certain types of cancer. Figures 4 and 5 report chemical structures of selected bioactive molecules present in Olea Europea L. products and by-products that will be here after commented.

\section{Olives}

Olives have a low sugar content (2.6-6\%) and a high oil content (12-30\%), these concentrations varying according to period of the year and variety. The beneficial effects of table olives are mainly associated with minor components such as phenols and tocopherols. The phenol profile is complex and depends on factors such as cultivar, irrigation, ripeness and post-harvest processing [18].
The main phenols in the leaves and fruits of the olive tree are oleuropein and ligstroside that impart a bitter taste and are found mainly in the skin and around the seed. They defend the fruits against pathogens and herbivores, making them unpalatable and unsuited for direct consumption from the plant [18]. To become edible, olives must be chemically treated to remove their bitter flavour. The most common industrial methods are:

- the Seville method for green olives, involving treatment with caustic soda that hydrolyses oleuropein to hydroxytyrosol and elenolic acid; subsequent lactic fermentation causes changes in the phenolic composition of the olives [19];

- the Californian system for black olives that involves initial conservation in brine, which decreases the concentration of oleuropein by bacterial metabolic degradation and increases aglycone derivatives and hydroxytyrosol. The olives are then sweetened with caustic soda, washed and oxidised by saturating the water with compressed air. This causes oxidative polymerisation of o-diphenols [20];

- the Greek or natural system which involves placing the olives in brine as soon as they are harvested. Under these condition, natural fermentation of the olives lowers oleuropein levels and polymerises anthocyanins, helping to stabilise colour [21].

The main chemical reaction are briefly represented in Figure 6.

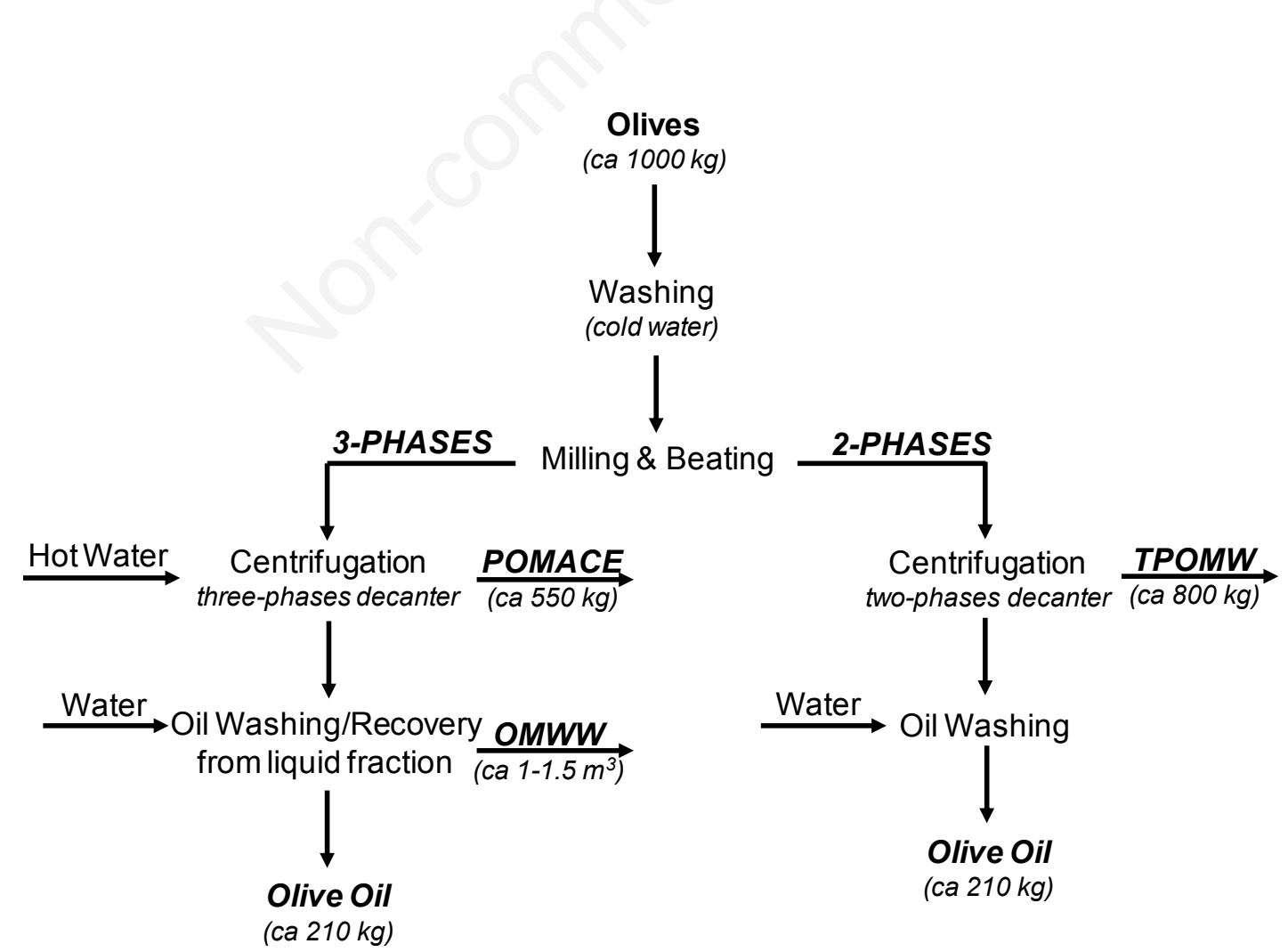

Figure 3. Scheme of three-phase and two-phase systems for olive oil extraction (OMWW, Olive Mill Waste Water; TPOMW, Thick Paste Olive Mill Waste, moist pomace). 


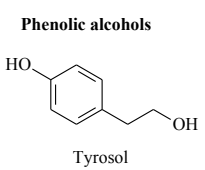

Tyroso

Secoiridoids<smiles>C/C=C1/C(OC2OC(CO)C(O)C(O)C2O)OC=C(C(=O)OC)[C@H]1CC(=O)OCCc1ccc(O)cc1</smiles>

$\mathrm{HO}_{\mathrm{OH}}$
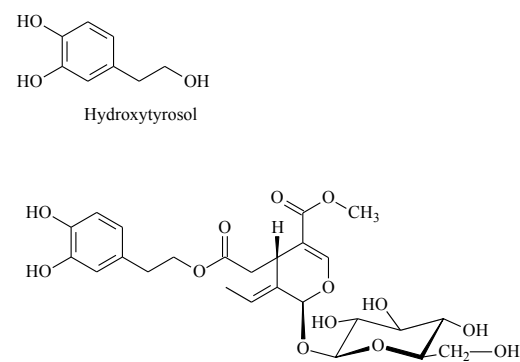

Oleuropein<smiles>O=C(O)/C=C/c1ccc(O)c(O)c1</smiles><smiles>COc1cc(/C=C/C(=O)O)ccc1O</smiles><smiles>COc1cc(C(=O)O)ccc1O</smiles>

Caffeic acid

Ferulic acid

$p$-Coumaric acid

Vanillic acid<smiles>O=C(/C=C/c1ccc(O)c(O)c1)O[C@@H]1O[C@](O)(C(=O)O)CC(O)[C@H]1O</smiles>

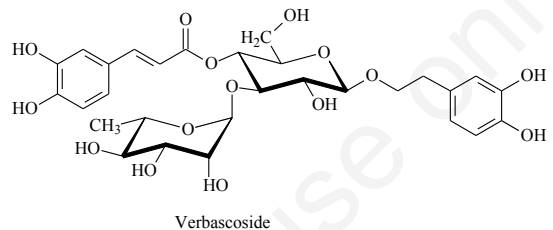

Figure 4. Chemical structures of selected bioactive phenolic alcohols, secoidiroids, and phenolic acids present in Olea Europea L. products and by-products.

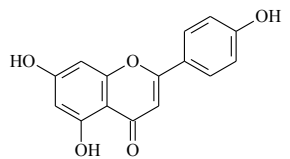

Apigenin
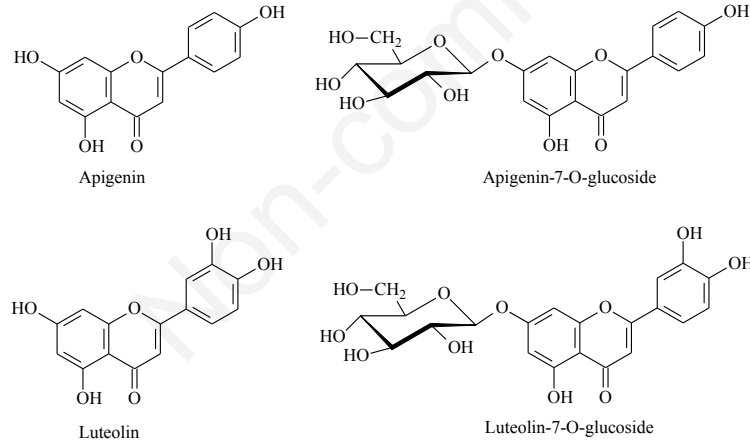

Apigenin-7-O-glucoside

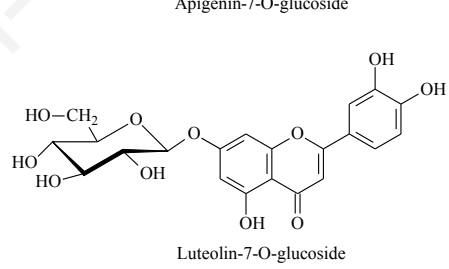

Luteolin-7-O-glucoside
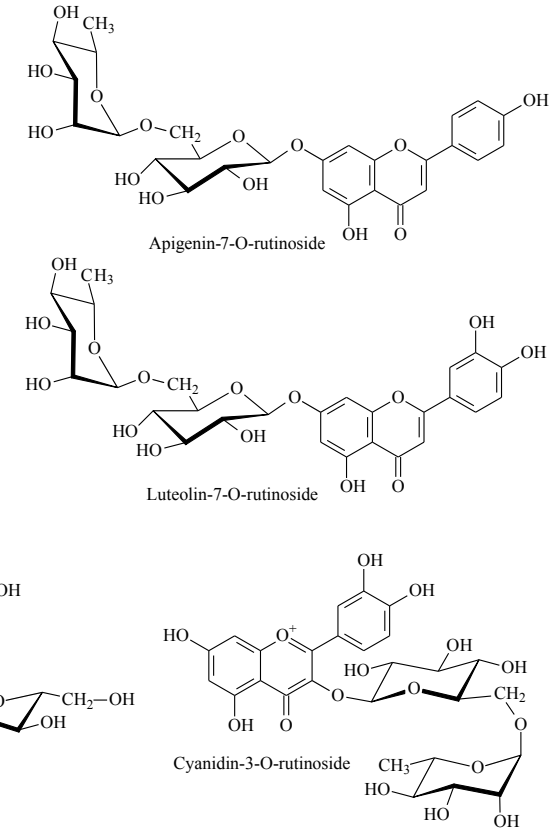

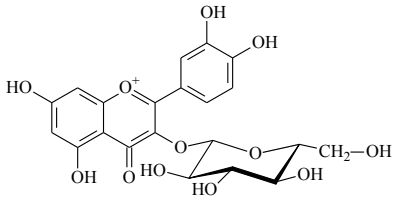

Cyanidin-3-O-glucoside<smiles>O=c1cc(-c2ccc(OC3OC4CC(O)C(CO)C(O)C3O4)c(O)c2)oc2cc(O)cc(O)c12</smiles>

Luteolin-4'-O-glucoside<smiles>O=c1c(O)c(-c2ccc(O)c(O)c2)oc2cc(O)cc(O)c12</smiles>

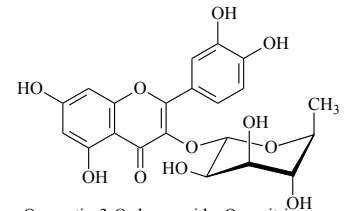

Quercetin-3-O-hhamnoside, Quercitrin

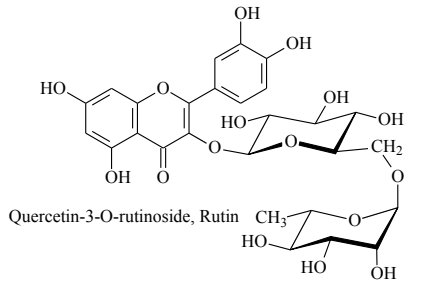

Figure 5. Chemical structures of selected bioactive flavonoids present in Olea Europea L. products and by-products. 
Total phenol compounds in olives are $1-3 \%$ by weight of fresh pulp [22]. The main classes of phenols are phenolic alcohols, phenolic acids, flavonoids and secoiridoids (Figures 4 and 5). Phenolic acids are the simplest polyphenols in olives and the most abundant are caffeic acid, chlorogenic acid and the more complex verbascoside. The most abundant phenolic alcohols in olives are hydroxytyrosol and tyrosol and their glycosides. Hydroxytyrosol and tyrosol are derived from hydrolysis of oleuropein and ligstroside, respectively (Figure 4). Hydroxytyrosol is a polyphenol with a strongly antioxidant catecholic portion, and it is reported in literature as having many health-promoting properties including being an immunostimulant, antibacterial agent and inhibitor of atherosclerotic plaque formation $[23,24]$.

Flavonoids are the principal dietary phenol intake. They are strong antioxidants, reducing the incidence of cardiovascular disease and certain types of cancer [27] The main flavonoids in olives are luteolin-7-O-glucoside, cyanidin-3-O-glucoside, cyanidin-3-O-rutinoside, rutin, apigenin-7-O-glucoside, quercetin-3-O-rhamnoside and luteolin (Figure 5, Table 2).[25,26]

Secoiridoids are only found in a small group of edible plants. The major ones are oleuropein, ligstroside and demethyloleuropein (Figure 4). Oleuropein is the ester between hydroxytyrosol and elenolic acid, whereas ligstroside is the ester between tyrosol and elenolic acid. Oleuropein is generally the predominant phenol in olive cultivars and is found in the fruits and leaves. Demethyloleuropein is only found in certain varieties of olive and can therefore be exploited as a marker of variety (Table 2) [26].

The phenol profile of olives varies considerably dur- ing ripening. In early stages of the growth and development of fruits, oleuropein levels increase to a maximum of $14 \%$ dry weight basis [22]. This is followed by a green ripeness phase in which oleuropein decreases and levels of hydroxytyrosol increase, probably due to hydrolysis by $\beta$-glucosidase and esterases involved in the breakdown of oleuropein, first producing oleuropein aglycone and subsequently hydroxytyrosol (Figure 7) [28]. However, certain authors report that the decrease in oleuropein is not always accompanied by an increase in hydroxytyrosol: in some case both decrease during ripening [29]. This may be due to formation of phenol oligomers when oleuropein is polymerised by diphenoloxidase [30]. In this phase there is also a decrease in the level of chlorophyll in the fruits. Finally, in the black ripeness phase, oleuropein continues to decrease while anthocyanins and flavonoids, such as luteolin-7-O-rutinoside, cyanidin-3-O-glucoside, cyanidin-3-O-rutinoside and rutin, increase.

Oleuropein is involved in the browning process of olives after impact and breaking during harvesting and during subsequent treatments. Browning is due to the action of $\beta$-glucosidase and esterase on oleuropein and oleuropein aglycone, respectively, with formation of hydroxytyrosol. After this, oleuropein, hydroxytyrosol and verbascoside are oxidised by polyphenoloxidase [22]

Finally, it is interesting to report that oleuropein aglycone, as well as ligstroside aglycone, can be present in many different isomers, that have been previously characterised (via mass spectrometry), elucidating also possible transformations among them (Figure 8) [31-32].

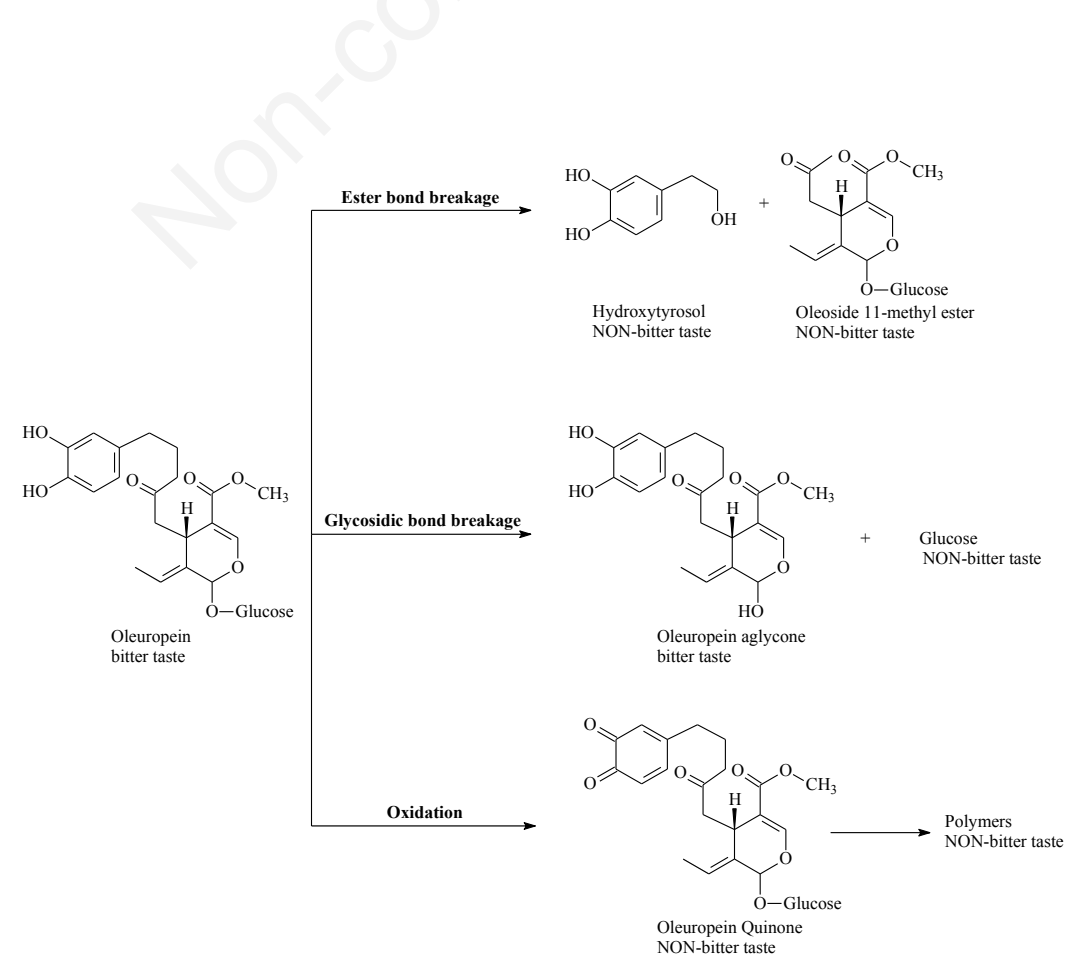

Figure 6. Main chemical reactions involved in the industrial process to remove the bitter flavour from olives. 


\section{Leaves}

Many of the polyphenols in the fruit of the olive tree are also found in the leaves. The Mediterranean region has long periods of sunlight and many pathogens and insects that can attack olive trees. To combat these stresses the olive produces large quantities of polyphenols that are stored in the leaves of its canopy. The concentration and type of polyphenols in the leaves is influenced by many factors, such as geographical location, cultivar and age of plant [33]. The main phenol encountered in olive leaves is the secoiridoid oleuropein, whereas its analogues oleuropein aglycone and ligstro- side aglycone occur in variable concentrations (Table 3) [34-37]. The second most abundant compound in olive leaves is the phenolic alcohol hydroxytyrosol, whereas tyrosol is only found in small concentrations in leaves. Other related compounds from leaves are verbascoside, caffeic acid and $p$-coumaric acid. Leaves also contain a series of flavonoids that constitute $2 \%$ of total polyphenols content. Major examples are luteolin, apigenin and rutin (Table 3 ).

Other compounds found in smaller quantities are oleanolic acid, vanillin and vanillic acid. According to the literature, young leaves of olive trees contain high
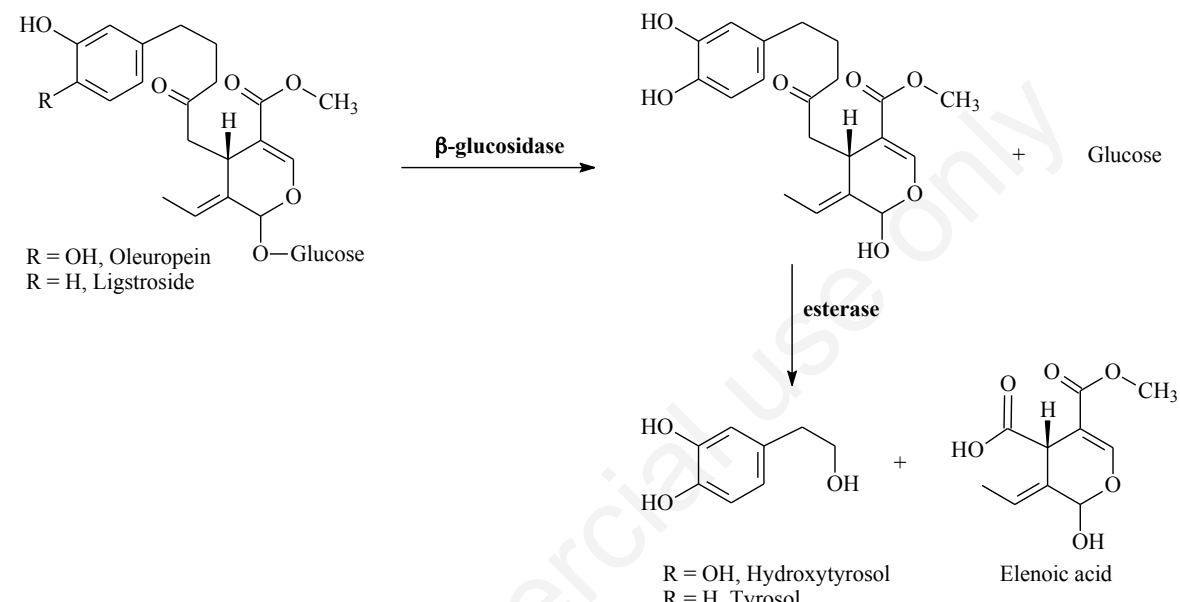

Figure 7. Enzymatic hydrolyses naturally occurring during the ripeness process of olives.

Table 2. Contents of selected phenolic alcohols, phenolic acids, flavonoids and secoiridoids analysed in olive fruits (values expressed as $\mathrm{mg} / \mathrm{kg} \mathrm{dw}$ ).

\begin{tabular}{|c|c|c|}
\hline Compounds & Ranges & References \\
\hline Oleuropein & $340-21,700$ & {$[25]$} \\
\hline Ligstroside & $900-11,400$ & [26] \\
\hline Demethyloleuropein & Trace-4400 & [26] \\
\hline Hydroxytyrosol & $1480-15,760^{*}$ & {$[25]$} \\
\hline Tyrosol & Trace-700 & [26] \\
\hline Chlorogenic acid & Trace- 10 & {$[25]$} \\
\hline Verbascoside & Trace-2 10 & {$[25]$} \\
\hline Luteolin-7-O-glucoside & $12-690$ & {$[25]$} \\
\hline Luteolin & $3-440$ & {$[25]$} \\
\hline Quercetin-3-O-rhamnoside & Trace-190 & {$[25]$} \\
\hline Cyanidin-3-O-glucoside & Trace- 1060 & {$[25]$} \\
\hline Cyanidin-3-O-rutinoside & Trace-1400 & {$[25]$} \\
\hline Apigenin-7-O-glucoside & $12-420$ & {$[25]$} \\
\hline
\end{tabular}

*Up to 27,900 and $71,350 \mathrm{mg} / \mathrm{kg} \mathrm{dw}$, in two samples [25]. 
concentrations of oleuropein, ligstroside and non glycosylated flavonoids, whereas older leaves contain larger concentrations of verbascoside, oleuroside and glycosylated forms of luteolin. This is explained by bioconversion of oleuropein and ligstroside into ver- bascoside and oleuroside during leaf growth and by bioconversion of flavonoid aglycones into their glycosylated forms (Figures 4 and 5) [38].

Leaves also contain tocopherols and $\beta$-carotene $[33,37]$. Leaves and unripe fruits of olive trees contain

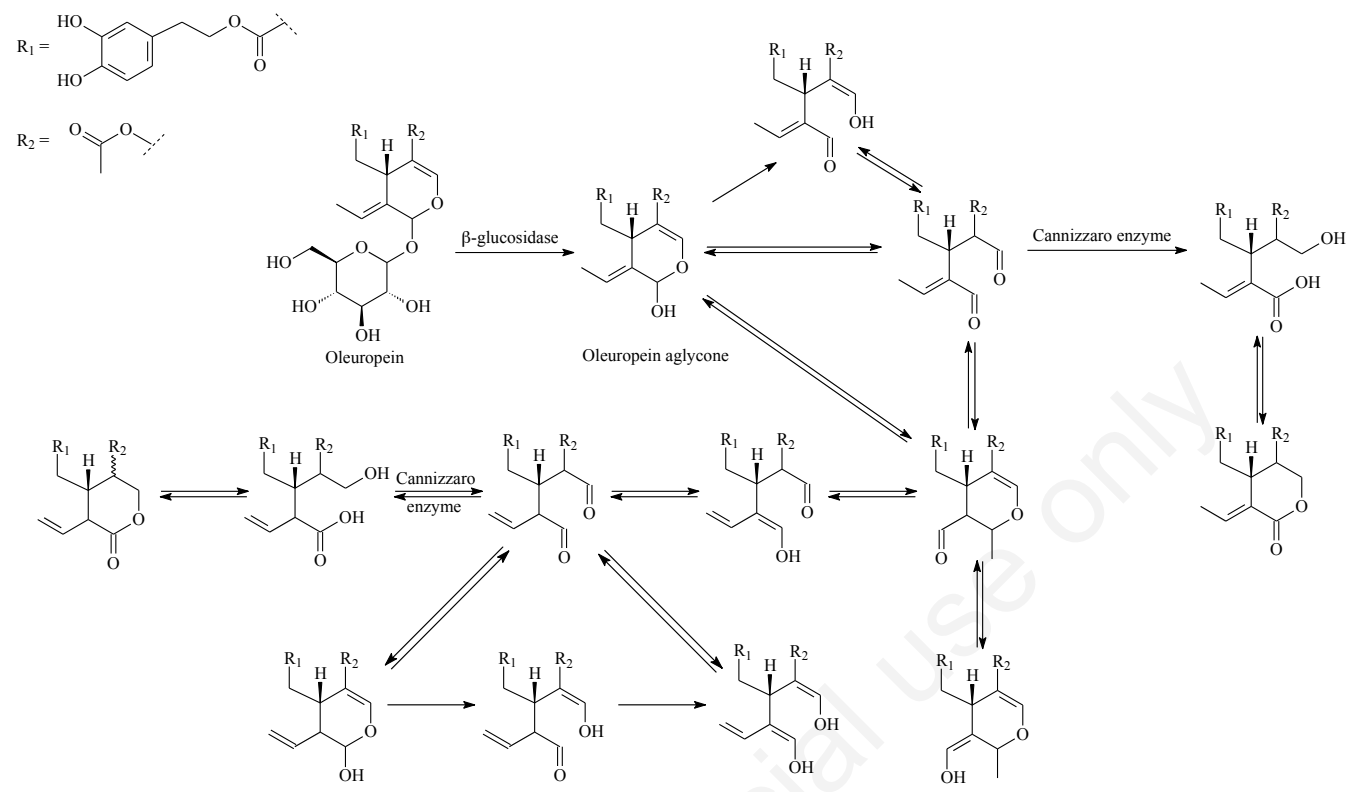

Figure 8. Oleuropein aglycones isomers molecular structures and proposed transformations among isomers during the fruit ripening, crushing and malaxing processes (cis or trans isomers are possible form many strucures, and are not here reported; adapted from Garcia-Mozo et al., 2009) [31].

Table 3. Contents of selected phenolic alcohols, phenolic acids, flavonoids and secoiridoids analysed in olive leaves (values expressed as $\mathrm{mg} / \mathrm{kg} \mathrm{dw}$ ).

\begin{tabular}{lcc}
\hline Compounds & Ranges & References \\
\hline Oleuropein & $5200-41,000 ; 530-5800$ & {$[33,34,35] ;[36]$} \\
\hline Hydroxytyrosol & Trace-8500 & {$[33,34]$} \\
\hline Tyrosol & Trace & {$[33]$} \\
\hline Chlorogenic acid & $3200-62,700$ & {$[36,37]$} \\
\hline Caffeic acid & $220-22,000$ & {$[35,36,37]$} \\
\hline$p$-Coumaric acid & $260-19,100$ & {$[36]$} \\
\hline Verbascoside & $200-1400$ & {$[33,35]$} \\
\hline Luteolin & 1900 & {$[33,34,35]$} \\
\hline Luteolin-7-O-glucoside & Trace-4200 & {$[34,35]$} \\
\hline Luteolin-4'-O-glucoside & $1360-3300$ & {$[34,37]$} \\
\hline Quercetin & $10-16400$ & {$[36]$} \\
\hline Quercetin-7-O-rhamnoside & 15,300 & {$[33,35]$} \\
\hline Rutin & $10-34,600$ &
\end{tabular}


pigments, the main function of which is to absorb sunlight and convert it into the energy necessary to synthesise carbohydrates from water and carbon dioxide by photosynthesis [39]. The type and quantity of pigments in plant tissues depends on factors such as species, variety, ripeness and growing conditions.

At the end of blooming (May-June; Figure 2), olives begin to develop. They ripen towards the end of $\mathrm{Au}$ tumn, turning purplish black. Before the fruits ripen, chlorophyll a is the most abundant pigment they contain (60-70\% of total pigments), followed by chlorophyll b $(15-20 \%)$. Carotenoids occurs in minor percentages, $\beta$-carotene being the most abundant (4$5 \%$ ), while violaxanthin and neoxanthin occur in similar percentages (4-5\%; Figure 9). When the olives begin to ripen, photosynthesis decreases and chlorophyll disappears, probably together with most of the carotenoids, whereas xanthophylls, which are prevalently esterified in olives, increase. When the olives are ripe, they are purplish in colour due to anthocyanins and the chloroplasts are replaced by chromoplasts [40]. In a study on olive leaves of the Neb jmel cultivar, collected in two different periods of the year [41], it was found that the concentration of total chlorophylls depends on the age of the leaves. The maximum concentrations of total chlorophyll ( $a$ and $b$ ) occurred in the Winter time, when the vegetative stage in not active (Winter $24 \mathrm{\mu g} / \mathrm{mL}$ of extracted solution). In Autumn, when the leaves are still growing, chlorophyll levels are lower $(10 \mu \mathrm{g} / \mathrm{mL}$ of extracted solution) and anthocyanin concentrations are higher (Autumn $1.4 \mathrm{mg} / \mathrm{kg}$ fresh weight, fw and Winter $0.8 \mathrm{mg} / \mathrm{kg} \mathrm{fw}$ ) [41].

\section{Oil}

The phenol profile of virgin olive oil depends strongly on the chemical composition of the olives and the process used to extract the oil, such as milling and malaxation conditions [28]. The organoleptic characteristics of the oil, such as aroma and flavour, are largely due to minor components, such as volatile compounds and phenols. Olive quality is certainly the most important factor for the quality of the finished product and is influenced by many factors, such as olive cultivar, ripeness, climate, soil and irrigation. $\otimes-$ Tocopherol (Figure 10) accounts for about $90 \%$ of total tocopherols ( 8 vitamers of vitamin E) in olive oil. The concentration of $\otimes$-tocopherol is on average more than $170 \mathrm{mg} / \mathrm{kg}$ oil (Table 4) [42-45]. The reasons for such high $\otimes$-tocopherol levels could be related to the need to reduce the concentration of radicals (singlet oxygen) generated during photosynthesis.

The major phenols found in olive oil are hydroxytyrosol, tyrosol and vanillic acid (simple phenols), the secoiridoids oleuropein and ligstroside and their aglycones, the flavonoids, and finally the lignans (pinoresinol and 1-acetoxypinoresinol, Figure 11). Hy-

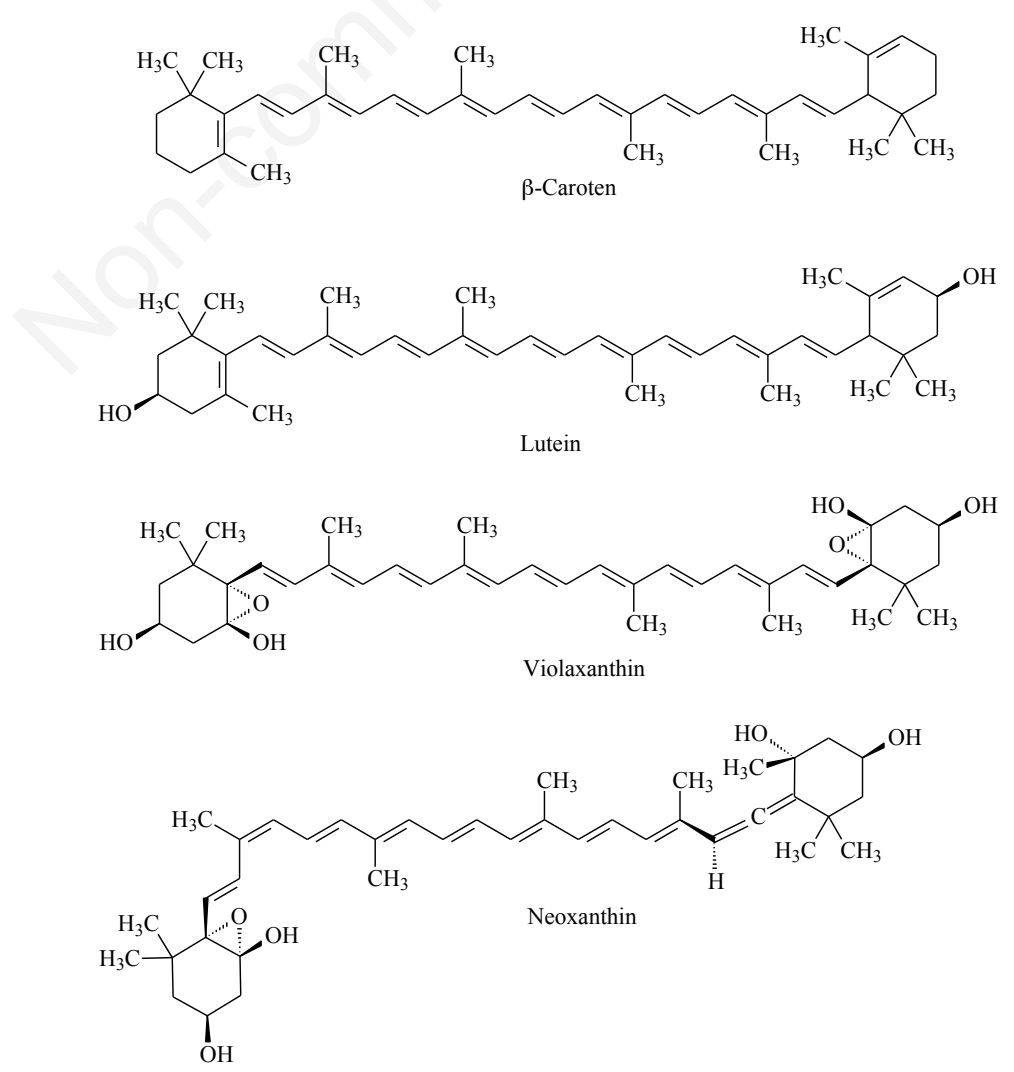

Figure 9. Chemical structures of selected carotenoids present in Olea Europea L. products and by-products. 
droxytyrosol is found in much greater quantities in extra virgin olive oil $(14.4 \pm 3.0 \mathrm{mg} / \mathrm{kg})$ than in refined virgin olive oil $(1.7 \pm 0.8 \mathrm{mg} / \mathrm{kg})$ [44]. The lignans pinoresinol and 1-acetoxypinoresinol are among the main antioxidants in olive oil. Pinoresinol is found in various plants, including those of the genus Forsythia (Family Oleaceae) [46], whereas 1-acetoxypinoresinol is also found in olive bark $[47,48]$. The fact that they do not occur in olive skins, leaves or branchlets suggests that they form in the oil during olive processing and pressing [49].

A phenol of great interest found in olive oil is the dialdehyde of dicarboxymethyl ligstroside aglycone, also known as oleocanthal (Figure 12, Table 4). First identified by Montedoro and coworkers [50] it is considered responsible for the sharp flavour of certain extravirgin olive oils [51]. It was isolated by Beauchamp and coworkers [52], and identified as a natural non steroid anti-inflammatory drug, the properties of which can be ascribed to structural analogy with ibuprofen. Long-term intake of small doses of oleocanthal through olive oil consumption can be linked to the lower incidence of cardiovascular disease, certain types of cancer and other degenerative diseases associated with the Mediterranean diet [53]. The dialdehyde of dicarboxymethyl oleuropein aglycone, known as oleacein, has similar properties to oleuropein as well as being a stronger antioxidant than hydroxytyrosol [54]. It is reported in literature that the concentration ratio of oleacein to oleocanthal (Figure 12) in various types of extravirgin olive oil depends on plant variety and is independent of the process by which olives are pressed to obtain oil [45]. It was also observed that the highest levels of the two compounds occur in oil samples prepared from early-picked green olives, whereas oils from ripe olives of the same variety, obtained by the same process, contain less of these compounds. The oleacein:oleocanthal ratio measured in oil samples decreases by an average of $10-15 \%$ after 12 months of storage in dark bottles in a cool dry place, indicating that oleacein is reduced comparatively more by oxidation.

Olive oil also contains many pigments, like chlorophyll, in the form of pheophytins, as well as carotenoids of which $\beta$-carotene is the most abundant while lutein occurs in traces (Figure 9). The antioxidant properties of these pigments contribute to the oxidative stability of olive oil [55].<smiles>CC(C)=CCC/C(C)=C/CC/C(C)=C/CCC1(C)CCC2C(C)C(O)C(C)C(C)C2O1</smiles>

Figure 10. Chemical structures of $\alpha$-tocoferol.<smiles>COc1cc(C2OCC3C(c4ccc(O)c(OC)c4)OCC23)ccc1O</smiles>

Pinoresinol<smiles>COC(=O)C12COC(c3ccc(O)c(OC)c3)C1COC2c1ccc(O)c(OC)c1</smiles>

1-Acetoxypinoresinol

Figure 11. Chemical structures of pinoresinol and l-acetoxypinoresinol (lignans).<smiles>CC=C(C=O)C(CC=O)CC(=O)OCCc1ccc(O)cc1</smiles>

Oleocanthal<smiles>C/C=C(/C=O)C(CC=O)CC(=O)OCCc1ccc(O)c(O)c1</smiles>

Oleacein

Figure 12. Chemical structures of oleocanthal and oleacein. 
Pomace and olive mill waste waters

The three-phase oil extraction process produces two main by-products: solid pomace and an aqueous fraction or waste water. A major problem of the olive oil industry is the treatment and disposal of this waste water, which is an environmental contaminant by virtue of its odour, acid pH (5-5.5) and its content of potassium salts, phosphates and organic matter such as fats, proteins, sugars and organic acids. It also contains a stable emulsion of olive pulp, mucilage, pectins and oil [56]. Attention was recently focused on how to exploit these by-products. Uses such as for energy, compost/fertiliser and feed supplements for livestock were proposed [15]. Pomace and waste water are also a major source of polyphenols that could be recovered as bioactive compounds for the pharmaceutical industry $[57,58]$. The phenol fraction in olive oil is only $2 \%$ of the total phenols of olives: the other $98 \%$ remains in the by-products. These products can occur naturally or arise from processing, partitioning in the oil and waste products [59]. The main phenols in pomace and waste waters are hydroxytyrosol, oleuropein, tyrosol, caffeic acid, $p$-coumaric acid, vanillic acid, verbascoside, elenolic acid and rutin (Figures 4 and 5, Table 5) [56,60-64]. Cicerale and coworkers [65] report that pomace is also an excellent source of oleocanthal, the chemical and biological properties of which have already been described.

\section{ANALYSIS OF THE ANTIOXIDANT PROPERTIES OF OLIVES, EXTRAVIRGIN OLIVE OIL, POMACE AND OLIVE LEAVES}

Here we report the results of analysis of the antioxidant activity of olives, extravirgin olive oil (EVOO, main product) and above all pomace (by-product) and olive leaves from cultivations and farms in SW Tuscany in the period 2013-2015.

All samples were pre-treated by freeze-drying and stored in the dark at $-20^{\circ} \mathrm{C} \pm 1$ until analysis. All were extracted with a non toxic solvent or solvent mixture [100\% $\mathrm{H}_{2} \mathrm{O} ; 100 \%$ EtOH; EtOH/ $\mathrm{H}_{2} \mathrm{O}(80 / 20 \%$, v/v)]. The best extraction of antioxidant compounds was obtained with the ethanol-water mixture.

Samples were analysed chemically for antioxidant activity by the TEAC (Trolox Equivalent Antioxidant Capacity) spectrophotometric test and for total polyphenols by the spectrophotometric method of Folin-Ciocalteau. Selected polyphenols (hydroxytyrosol and oleuropein) and members of the flavonoids and hydroxycinnamic acids were quantified by chromatography (HPLC-UV and HPLC-MS).

\section{ABTS and DPPH assays (Trolox Equivalent Antioxidant Capacity, TEAC) and Folin-Ciocalteau assay (Total PolyPhenols, TPP)}

TEAC measures the reducing power of antioxidant

Table 4. Contents of selected phenolic alcohols, phenolic acids, flavonoids and secoiridoids analysed in olive oils (values expressed as $\mathrm{mg} / \mathrm{kg}$ ).

\begin{tabular}{|c|c|c|}
\hline Compounds & Ranges & Reference \\
\hline$\alpha$-Tocopherol & $100-240$ & {$[42]$} \\
\hline Oleuropein & Trace & [43] \\
\hline Hydroxytyrosol & $1.7-14.0$ & {$[43,44]$} \\
\hline Tyrosol & $2.5-6.7$ & [43] \\
\hline Caffeic acid & Trace & {$[43]$} \\
\hline Ferulic acid & Trace- 0.2 & [43] \\
\hline$p$-Coumaric acid & Trace-1.0 & {$[43]$} \\
\hline Vanillic acid & Trace- 0.7 & [43] \\
\hline Apigenin & $0.6-3.3$ & [43] \\
\hline Luteolin & $1.6-6.6$ & {$[43]$} \\
\hline Pinoresinol & $0.9-48$ & {$[42,43]$} \\
\hline 1-Acetoxypinoresinol & $13-31$ & {$[42]$} \\
\hline Oleocanthal & $180-350$ & [45] \\
\hline Oleacein & $100-290$ & {$[45]$} \\
\hline
\end{tabular}


species on the basis of their capacity to reduce coloured radicals, such as the cationic radical ABTS ${ }^{\circ+}$ (ABTS, 2,2-azino-bis(3-ethylbenzothiazolin-6-sulphonic) acid) and the radical $\mathrm{DPPH}^{*}(2,2$-diphenyl-1-picrylhydrazyl radical) causing colour loss $[66,67]$. TEAC values for unknown compounds are expressed as equivalent concentration of Trolox, used to construct the calibration curve (Trolox, 6-hydroxy-2,5,7,8-tetramethylchroman2-carboxylic acid, standard water-soluble antioxidant analogue of vitamin E; TEAC/ABTS and TEAC/DPPH, $\mathrm{mmol}(\operatorname{Trx}) / \mathrm{kg}$ dry weight, dw). Total polyphenols (TPP) were determined by a colorimetric method based on the Folin-Ciocalteau reagent $[68,69]$. Values of unknown samples were expressed as equivalent concentration of gallic acid (3,4,5-trihydroxybenzoic acid) used to construct the calibration curve (TPP, $\mathrm{mg}(\mathrm{GA}) / \mathrm{kg} \mathrm{dw})$.

\section{EVOOs 2013-2014}

The TEAC/ABTS parameters of samples of EVOOs $2013(0.74 \pm 0.04-0.79 \pm 0.04 \mathrm{mmol}(\operatorname{Trx}) / \mathrm{kg} \mathrm{dw})$ and EVOOs $2014(1.61 \pm 0.04-0.77 \pm 0.05 \mathrm{mmol}(\operatorname{Trx}) / \mathrm{kg}$ $\mathrm{dw})$ were slightly lower than reported in literature (1.5-2.7 mmol(Trx)/kg dw; [70]. The values were nevertheless comparable because the samples analysed in this study were hydroalcoholic extracts of EVOO, whereas those reported in the cited paper were merely diluted without any preliminary extraction; thus the TEAC value includes the fat-soluble antioxidant component. For total polyphenols, however values were higher $(237 \pm 2-517 \pm 35 \mathrm{mg}(\mathrm{AG}) / \mathrm{kg} \mathrm{dw})$ than litera- ture values for hydroalcoholic extracts $(60 / 40 \%$, v/v; range 44-140 $\mathrm{mg}(\mathrm{AG}) / \mathrm{kg} \mathrm{dw}$ [71].

\section{Pomace 2013-2015}

Particular attention has been paid to pomace as a byproduct of olive oil production and as a potential source of antioxidant molecules. The pomace samples showed very high TEAC/ABTS and TPP antioxidant activities, mostly in 2015 samples (Figure 13), especially samples P15-D/J: TEAC/ABTS, $265 \pm 10-388 \pm 12$ $\mathrm{mmol}(\operatorname{Tr} \mathrm{x}) / \mathrm{kg} \mathrm{dw}$; TPP, $26.0 \pm 1.5-43.7 \pm 3.0 \mathrm{mg}(\mathrm{GA}) / \mathrm{g}$ $\mathrm{dw}$. The 2014 samples had much lower values indicating a particularly poor harvest.

Interestingly, the TEAC/ABTS and TPP parameters showed a linear correlation in 2013-2014 and 2015 pomace samples $\mathrm{R}^{2}=0.763(\mathrm{f}(\mathrm{x})=8.379 \mathrm{x})$ improving to $\mathrm{R}^{2}=0.825(\mathrm{f}(\mathrm{x})=8.418 \mathrm{x})$ in 2015 samples and $\mathrm{R}^{2}=0.941$ $(f(x)=7.661 x$; Figure 14) when samples P13-A, P15-I and P15-J were excluded. These samples were from geographical areas peripheral to the production area of the other samples.

Kinetic decay analysis of antioxidant activity (TEAC/ABTS) was performed on 2013 pomace sample (P13-A) divided into aliquots that underwent different pretreatment and storage protocols. Specifically: i) portions of freeze-dried sample (stored at $-20^{\circ} \mathrm{C} \pm 1 ; 4^{\circ} \mathrm{C} \pm 1$ and $20^{\circ} \mathrm{C} \pm 2$ ), extracted daily with ethanol and analysed; ii) portions of liquid fraction obtained by centrifuge, stored at $-20^{\circ} \mathrm{C} \pm 1,4^{\circ} \mathrm{C} \pm 1$ and $20^{\circ} \mathrm{C} \pm 2$, and analysed daily; iii) portions of ethanol extracts of freeze-dried pomace stored at $-20^{\circ} \mathrm{C} \pm 1,4^{\circ} \mathrm{C} \pm 1$ and

Table 5. Contents of selected phenolic alcohols, phenolic acids, flavonoids and secoiridoids analysed in olive waste waters and pomaces (values expressed as $\mathrm{mg} / \mathrm{L}$ and $\mathrm{mg} / \mathrm{kg}$, respectively).

\begin{tabular}{lcccc}
\hline Compounds & Ranges waste water & Reference & Ranges pomace & Reference \\
\hline Oleuropein & & 82 & {$[64]$} \\
\hline Oleuropein aglycone & & 24 & {$[64]$} \\
\hline Ligstroside aglycone & & $27-31$ & {$[64]$} \\
\hline Hydroxytyrosol & $20-130$ & {$[56]$} & $8-10$ & {$[64]$} \\
\hline Tyrosol & $1-10$ & {$[56]$} & 21 & {$[64]$} \\
\hline Caffeic acid & Trace-4 & {$[56]$} & $7-14$ & {$[64]$} \\
\hline Ferulic acid & & & $9-10$ & {$[64]$} \\
\hline$p$-Coumaric acid & & {$[56]$} & {$[64]$} \\
\hline Verbascoside & $24-165$ & {$[56]$} & & {$[64]$} \\
\hline Luteolin & Trace-623 & {$[56]$} & & \\
\hline luteolin-7-O-glucoside & Trace-366 & {$[56]$} & $62-128$ & {$[65]$} \\
\hline Rutin & $10-100$ & & & \\
\hline Oleocanthal & & & & \\
\hline
\end{tabular}


$20^{\circ} \mathrm{C} \pm 2$, and analysed daily. All experiments showed exponential decay. Figure 15 shows the decay of TEAC/ABTS for an ethanol extract of freeze-dried pomace stored at three different temperatures and analysed at regular intervals for $180 \mathrm{~h}$. Activity falls from 232 $\mathrm{mmol}(\operatorname{Tr} \mathrm{x}) / \mathrm{kg} \mathrm{dw}$ to about $50 \mathrm{mmol}(\operatorname{Tr} \mathrm{x}) / \mathrm{kg} \mathrm{dw}$ in about $48 \mathrm{~h}$, and faster at ambient temperature than under refrigeration. The kinetic decay experiment with the TEAC/ABTS parameter was repeated on 2014 pomace samples which showed a slight decline, explained by the fact that the initial antioxidant activity was much lower (mean $87 \mathrm{mmol}(\mathrm{Trx}) / \mathrm{kg} \mathrm{dw}$ ) and almost comparable with the plateau reached by sample P13A after $48 \mathrm{~h}$ under all the storage temperatures tested.

\section{EVOO samples enriched with pomace extracts}

Some preliminary attempts at enriching 2014 EVOO samples (EVOO14-A, EVOO14-B and EVOO14-C) with relevant pomace samples (P14-A, P14-B and P14C) extracted with ethanol/water $(80 / 20 \% \mathrm{v} / \mathrm{v})$ were made. The experiment used EVOOs (about 2 months old), stored in the dark at $-20^{\circ} \mathrm{C} \pm 1$. Before addition of pomace (EVOO14-A stored, 2 months), the parameter TEAC/ABTS showed values about $30 \%$ lower than in fresh samples (EVOO14-A fresh). The results (Figure 16) showed an increase in TEAC/ABTS for the first 48 $\mathrm{h}$ due to gradual release of oil-soluble antioxidants by the freeze-dried pomace. The measurements performed up to $72 \mathrm{~h}$ showed a decrease in the parameter, presumably due to simultaneous oxidation of the antioxidant species present in EVOO and pomace.

\section{Olive leaves}

Finally four samples of olive leaves of the Leccino variety, obtained at different stages of the phenological cycle of the plant (namely early Summer, early Autumn,

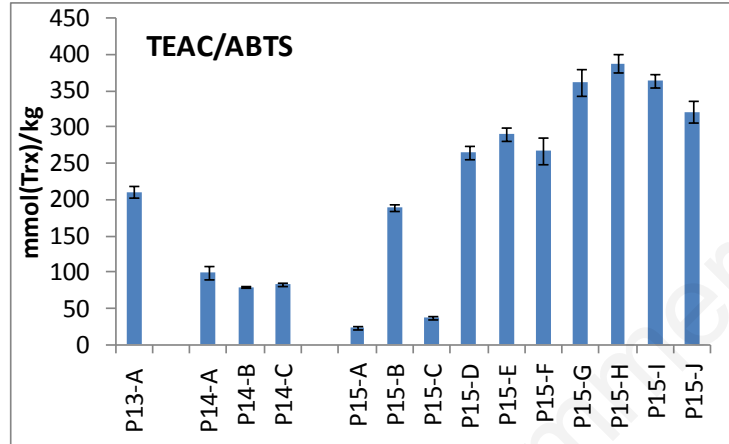

(a)

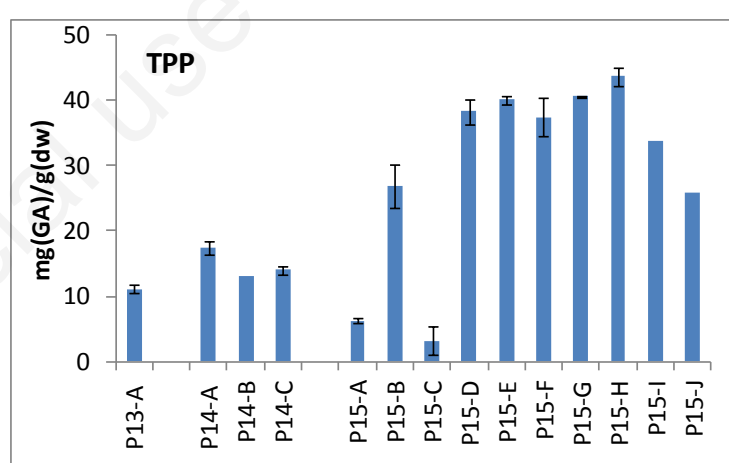

(b)

Figure 13. (a) TEAC/ABTS and (b) total polyphenol (TPP) antioxidant capacity of freezedried pomace samples (2013, 2014 and 2015$)$ extracted with $80 \%(\mathrm{v} / \mathrm{v})$ aqueous ethanol. Values are means of three replicates with standard deviation; $95 \%$ confidence interval.

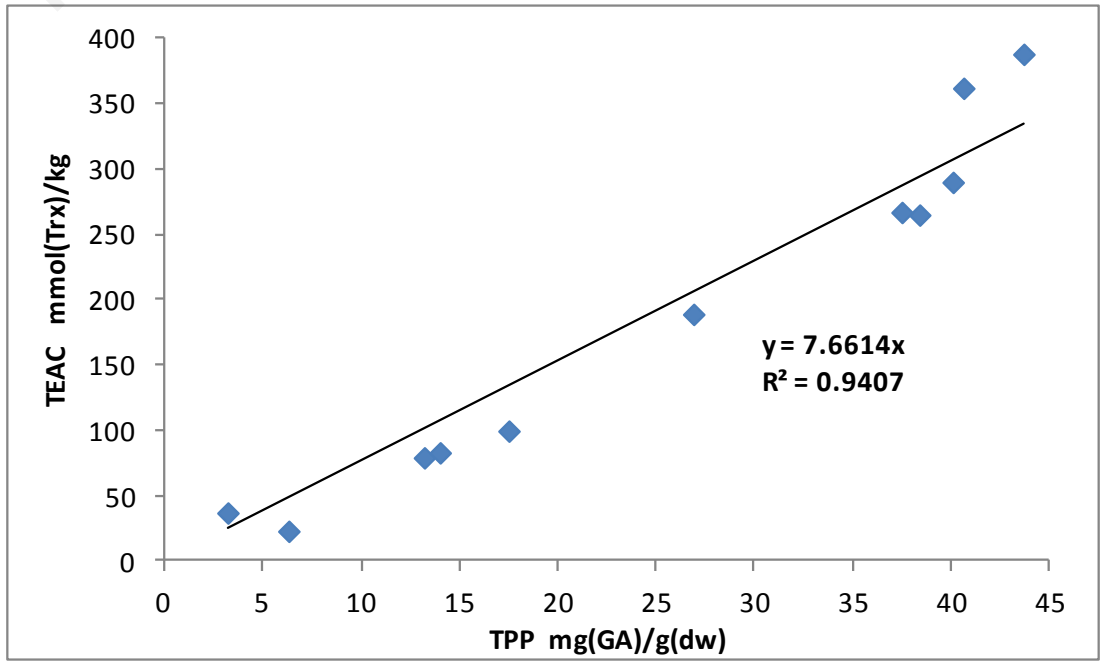

Figure 14. Correlation between TEAC/ABTS (mmol(Trx)/kg dw) and TPP (mg(GA)/g dw) for 2014 and 2015 samples of pomace. 
Winter and Spring) have been analysed. Total polyphenol content was in the range $117.9 \pm 5.9-203.5 \pm 10.2$ $\mathrm{g}(\mathrm{GA}) / \mathrm{kg} \mathrm{dw}$ in aqueous extracts and $219.5 \pm 11.0-$ $298.2 \pm 14.9 \mathrm{~g}(\mathrm{GA}) / \mathrm{kg} \mathrm{dw}$ in hydroalcoholic extracts (Figure 17a). A similar seasonal trend was observed for both types of extract and a $65 \%$ higher quantity of polyphenols was recorded in the hydroalcoholic extract than in the water extract, presumably due to the greater solubility of polyphenols in ethanol.
The results of the two assays of antioxidant activity (TEAC/ABTS and TEAC/DPPH) were in the intervals: TEAC/ABTS, $240.0 \pm 4.2-340.8 \pm 6.9$ and $286.7 \pm 15.7-$ $360.5 \pm 47.1 \mathrm{mmol}(\mathrm{Tr} x) / \mathrm{kg} \mathrm{dw}$, and TEAC/DPPH, $127.9 \pm 23.5-427.5 \pm 37.3$ and $342.5 \pm 9.0-499.8 \pm 9.8$ $\mathrm{mmol}(\operatorname{Trx}) / \mathrm{kg} \mathrm{dw}$ for water and hydroalcoholic extracts, respectively (Figure $17 \mathrm{~b}, \mathrm{c}$ ).

Under both extraction conditions, the trend of polyphenol content was in line with other studies in

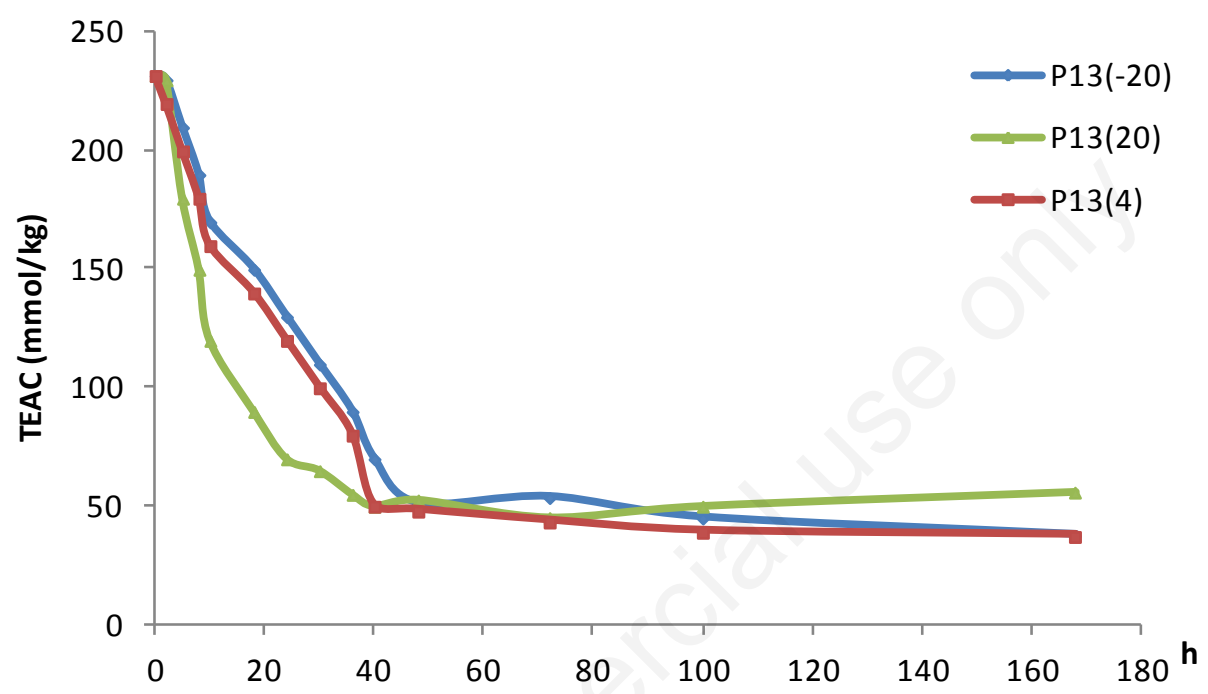

Figure 15. Decay of TEAC/ABTS in sample P13-A over $180 \mathrm{~h}$. The sample had been freezedried and extracted with absolute EtOH and stored at different temperatures $\left(-20^{\circ} \mathrm{C} \pm 1,4^{\circ} \mathrm{C} \pm 1\right.$ and $\left.20^{\circ} \mathrm{C} \pm 2\right) ; 95 \%$ confidence interval.

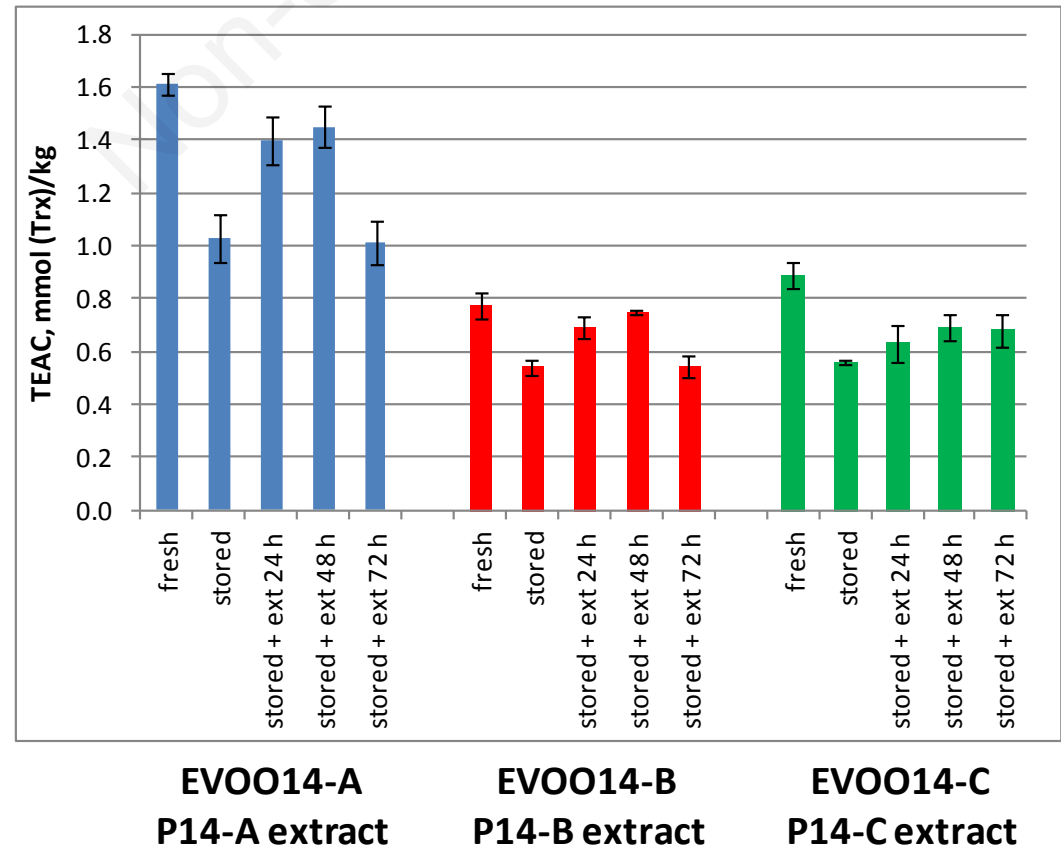

Figure 16. Antioxidant capacity (TEAC/ABTS) for EVOO samples enriched with their own pomace (2014). Values are means of three replicates; $95 \%$ confidence interval. 
the literature on olive leaf extracts from different varieties of Olea europaea during annual maturation of plants without irrigation or other treatments [72]. A similar trend was found in one of the two species studied (Kilis Yaglik) that showed highest concentrations in Winter, when vegetation stops, leaf and stem grow arrests and buds die. The lowest polyphenol content in leaves was found in Spring, when leaves grow relatively little whereas flower bunches begin to grow, continuing until late Spring/early Summer. Values increase slightly in Summer, when leaves and stems grow strongly and polyphenols are affected by increased sunlight (ultraviolet) and by drier soil conditions. This pattern is also closely correlated with antioxidant defences mounted by the plant. Antioxidants play a role in molecular mechanisms occurring in trees under different stresses (drought, salinity, low temperatures) that induce specific morphological adaptations, variations in water potential between leaves and roots and increased scavenging of oxygen free radicals. The high content of polyphenols in cold Winter months (a factor for poor vegetative production of olives trees, consequently defined as heliophilous) is confirmed in many studies $[36,73]$.

\section{HPLC-UV and HPLC-MS chromatography}

Samples of olive leaves were extracted with water $(100 \%)$ or $\mathrm{EtOH} / \mathrm{H}_{2} \mathrm{O}(80 / 20 \%, \mathrm{v} / \mathrm{v})$ and analysed for hy- droxytyrosol, oleuropein (secoiridoid), certain flavonoids and phenolic acids by HPLC-UV and HPLC-MS.

Figure 18 shows the superimposed chromatograms obtained by HPL-UV analysis of hydroalcoholic extracts of leaf samples obtained in different months for analysis of oleuropein and hydroxytyrosol (resveratrol was used as internal standard). Figures 19 and 20 show HPLC-MS chromatograms obtained in SIM and SRM modes (Single Ion Monitoring and Selected Reaction Monitoring), by injection of water and hydroalcoholic extracts of Leccino leaves (genistein was used as internal standard). Table 6 shows the range of polyphenols quantified.

\section{CONCLUSIONS}

The results show that the by-products of Olea europaea L. (leaves) and olive oil production (pomace) are promising sources of bioactive compounds. In leaves, compounds of interest are higher in periods when the vegetative cycle of the trees changes, coinciding with seasonal variations. Considering the health-giving effects of polyphenolic antioxidants and the importance of olive oil production in all Mediterranean countries, it is urgent to study all biologically active molecules for nutraceutical uses, for the production of functional foods and for other purposes

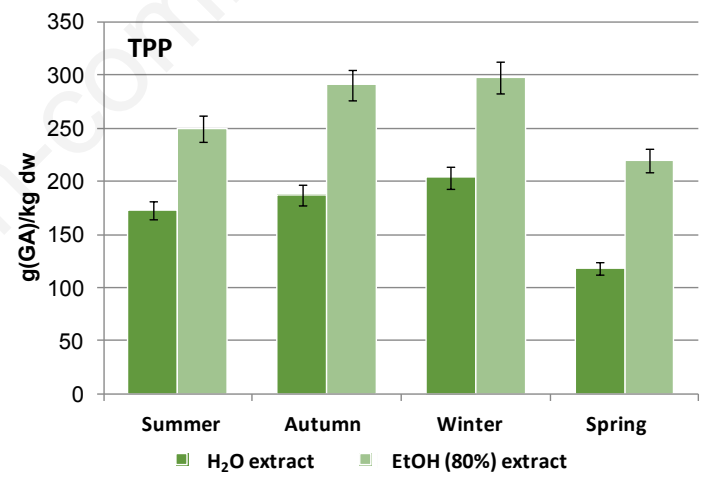

(a)
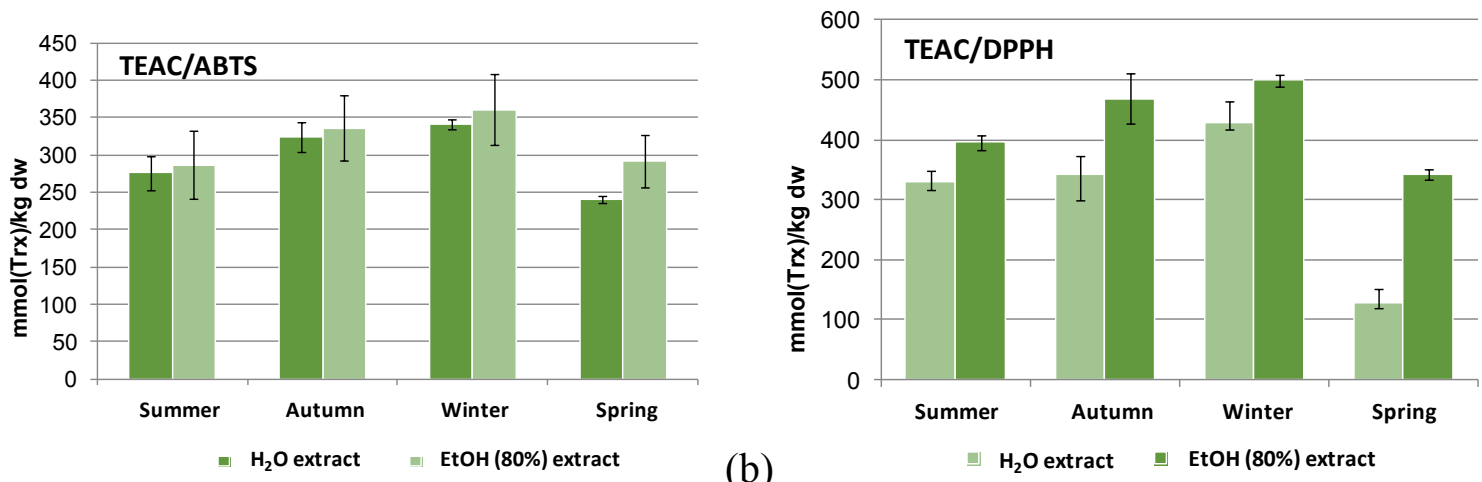

(c)

Figure 17. Antioxidant activity (a) TPP, (b) TEAC/ABTS and (c) TEAC/DPPH in water and hydroalcoholic extracts of olive leaves. Values are means of three replicates \pm standard deviation (SD). 
such as cosmetics. Promotion of the primary and secondary components of olive production is a model to use in other areas of agriculture (e.g. viticulture, hor- ticulture, cereal crops) to maximise the use of nutritional and nutraceutical resources and to make agriculture economically sustainable.

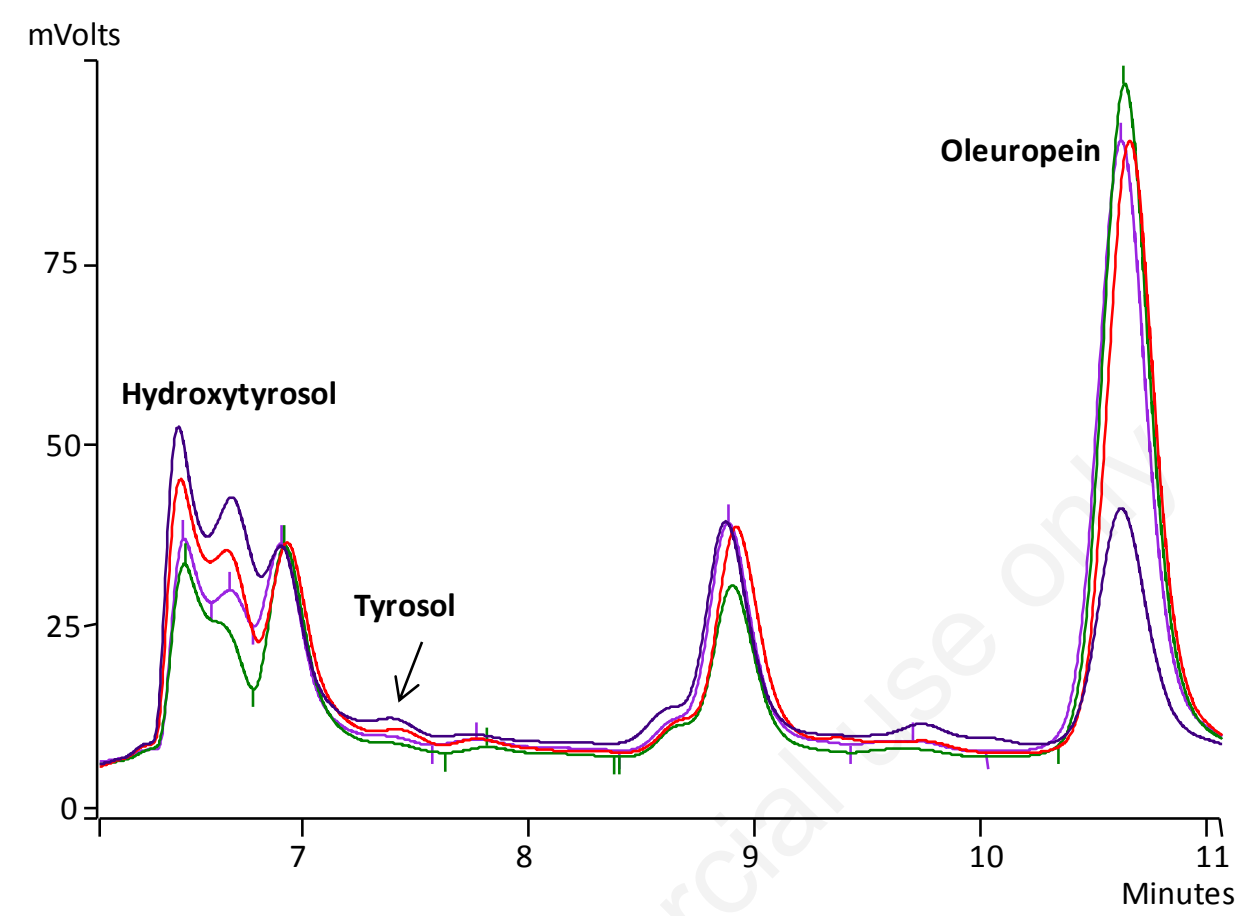

Figure 18. Overlapping HPLC-UV chromatograms in the oleuropein and hydroxytyrosol signal regions for hydroalcoholic extracts of olive leaves harvested in different seasons (green, Summer; violet, Autumn; red, Winter; blue, Spring).

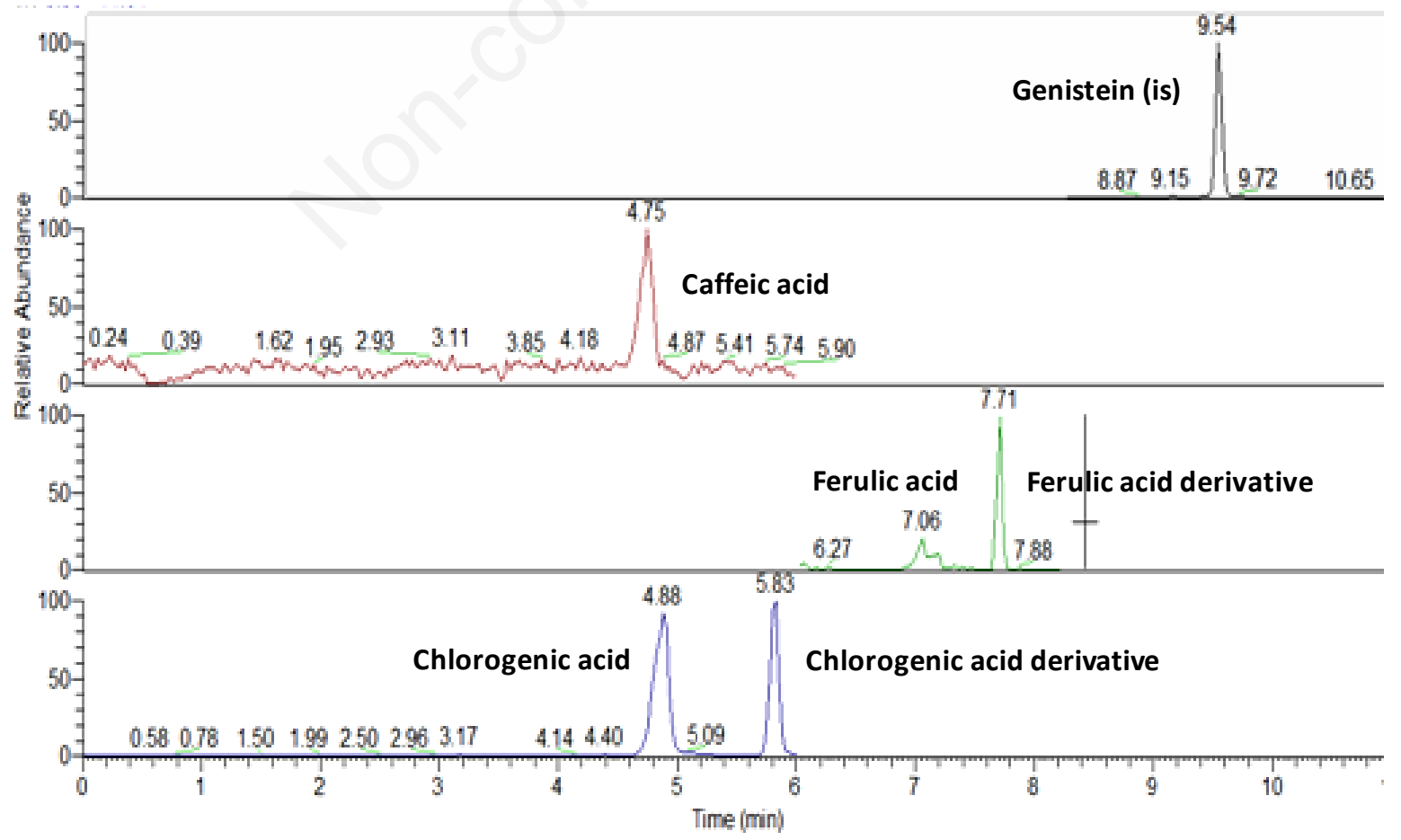

Figure 19. HPLC-MS chromatogram obtained by injection of aqueous extract of olive leaves (Winter) in the region of the peaks of hydroxycinnamic acid. 


\section{ACKNOWLEDGMENTS}

The authors thank the Tuscan Regional Adminis- tration for funding the project NUTRIforOIL and Toscana Life Sciences for the HPLC-MS measurements.

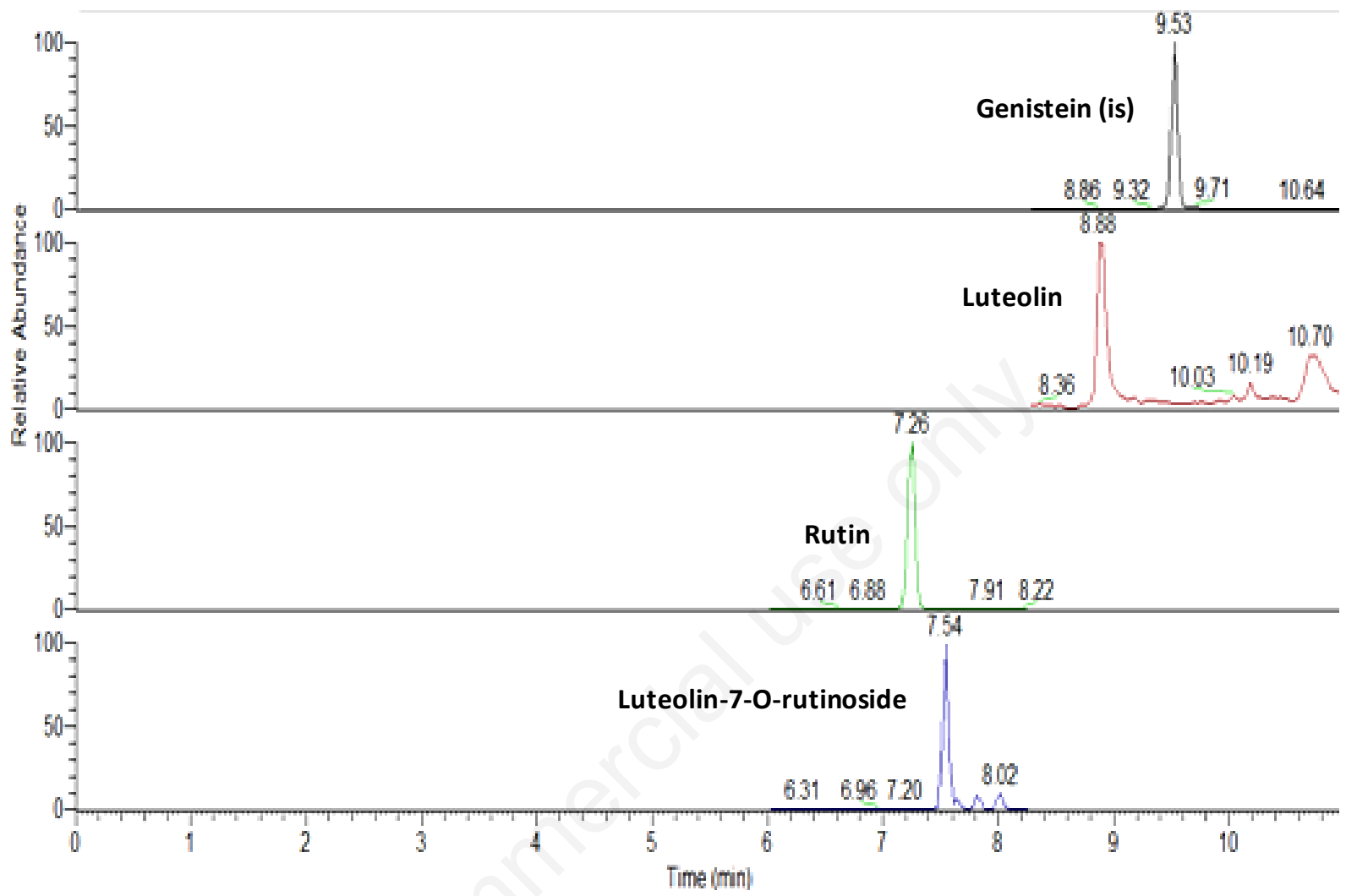

Figure 20. HPLC-MS chromatogram obtained by injection of hydroalcoholic extract of olive leaves (Winter) in the region of the peaks of flavonoids.

Table 6. Hydroxytyrosol, oleuropein and selected hydroxycinnamic acid and flavonoid content in water and hydroalcoholic extracts of olive leaves harvested in different months.

\begin{tabular}{lcc}
\hline & $\begin{array}{c}\text { Water extract } \\
\left(\mathbf{H}_{\mathbf{2}} \mathbf{O}, \mathbf{1 0 0}\right)\end{array}$ & $\begin{array}{c}\text { Hydroalcoholic extract } \\
\left(\mathbf{E t O H} / \mathbf{H}_{\mathbf{2}} \mathbf{O}, \mathbf{8 0} / \mathbf{2 0} \%, \mathbf{v} / \mathbf{v}\right)\end{array}$ \\
\hline Hydroxytyrosol $(\mathrm{g} / \mathrm{kg} \mathrm{dw})$ & $6.04 \pm 0.19-12.05 \pm 0.04$ & $8.37 \pm 0.38-14.73 \pm 0.52$ \\
\hline Oleuropein $(\mathrm{g} / \mathrm{kg} \mathrm{dw})$ & $1.86 \pm 0.11-19.00 \pm 0.64$ & $32.93 \pm 4.32-103.88 \pm 4.47$ \\
\hline Caffeic acid $(\mathrm{mg} / \mathrm{kg} \mathrm{dw})$ & $8.0 \pm 0.4-65.6 \pm 5.0$ & $8.8 \pm 1.1-48.9 \pm 5.6$ \\
\hline Ferulic acid $(\mathrm{mg} / \mathrm{kg} \mathrm{dw})$ & $11.3 \pm 3.6-23.9 \pm 3.9$ & $8.6 \pm 2.5-30.7 \pm 1.9$ \\
\hline Chlorogenic acid $(\mathrm{mg} / \mathrm{kg} \mathrm{dw})$ & $154.0 \pm 2.8-166.7 \pm 3.7^{*}$ & $66.2 \pm 1.3-262.8 \pm 2.6$ \\
\hline Ferulic acid derivative $(\mathrm{mg} / \mathrm{kg} \mathrm{dw})$ & $72.8 \pm 3.6-286.7 \pm 9.2$ & $43.2 \pm 3.1-162.9 \pm 1.1$ \\
\hline Chlorogenic acid derivative $(\mathrm{mg} / \mathrm{kg} \mathrm{dw})$ & $84.1 \pm 3.0-114.9 \pm 2.8^{*}$ & $24.6 \pm 1.3-124.4 \pm 11.3$ \\
\hline Rutin $(\mathrm{mg} / \mathrm{kg} \mathrm{dw)}$ & $8.3 \pm 1.3-667.5 \pm 16.0$ & $504.2 \pm 73.5-973.9 \pm 49.5$ \\
\hline Luteolin $(\mathrm{mg} / \mathrm{kg} \mathrm{dw)}$ & $26.9 \pm 1.5-141.9 \pm 8.4$ & $24.9 \pm 1.2-141.2 \pm 8.9$ \\
\hline Luteolin-7-O-rutinoside $(\mathrm{mg} / \mathrm{kg} \mathrm{dw})$ & $9.3 \pm 1.0-133.8 \pm 3.1$ & $113.6 \pm 17.2-170.5 \pm 19.2$ \\
\hline
\end{tabular}

Values are means of three replicates \pm standard deviation (SD).

"Trace values (<2 mg/kg dw) were detected in Spring. 


\section{REFERENCES}

1. Bartolini G, Petruccelli $R$, Tindall HD. Classification, origin, diffusion and history of the olive. Tindal HD, Menini UG, Eds. Rome: FAO; 2002

2. Kapellakis IE, Tsagarakis KP, Crowther JC. Olive oil history, production and by-product management. Rev Environ Sci Biotechnol 2008,7:1-26.

3. Breton CM, Warnock P, Berville AJ. Origin and history of the olive. In: Olive germplasm. The olive cultivation, table olive and olive oil industry in Italy. Muzzalupo I, Ed. InTechOpen, 2012. pp. 3-22.

4. Pellati R. La storia di ciò che mangiamo. Fondazione per lo studio degli alimenti e della nutrizione. Torino: Daniela Piazza Editore; 2013.

5 Kiple KF, Ornelas KC. Olive oil. The Cambridge world history of food. New York: Cambridge University Press; 2000.

6. Chiappetta A, Muzzalupo I. Botanical description. In: Olive germplasm. The olive cultivation, table olive and olive oil industry in Italy. Muzzalupo I, Ed. InTechOpen, 2012; pp. 23-38.

7. Baldoni L, Tosti N, Ricciolini C, et al. Genetic structure of wild and cultivated olives in the central Mediterranean basin. Ann Botany 2006;98:935-42.

8. Bartolini $G$, Prevost $G$, Messeri $C$, et al. Olive germplasm: cultivars and world-wide collections. Rome: FAO; 1998.

9. Lieth H. Phenology and seasonality modeling. Ecol Studies 1974;8.

10. Bernati E, Botarelli L, Nieddu G, et al. Scale di riconoscimento fenologico. In: Collana di Agrofenologia, Aspetti generali delle osservazioni agrofenologiche. Rome: SEA; 1999. pp. 18-53.

11. Meier U, Bleiholder H, Buhr L, et al. The BBCH system to coding the phenological growth stages of plants. History and publications. J Kulturflanzen 2009,61:41-52.

12 Sanz-Cortés F, Martínez-Calvo J, Badenes ML, et al. Phenological growth stages of olive trees (Olea europaea L.). Ann Appl Biol 2002;140:151-7.

13. Garcia-Mozo H, Orlandi F, Galan C, et al. Olive flowering phenology variation between different cultivars in Spain and Italy: modeling analysis. Theor Appl Climatol 2009,95:385-95.

14. Owen RW, Giacosa A, Hull WE, et al. Olive-oil consumption and health: the possible role of antioxidants. Lancet Oncol 2000;1:107-12.

15. Roig A, Cayuela ML, Sánchez-Monedero MA. An overview on olive mill wastes and their valorisation methods. Waste Manag 2006,26:960-9.

16 Montemurro F, Convertini G, Ferri D. Mill wastewater and olive pomace compost as amendments for rye-grass. Agronomie 2004; 24:481-6.

17. Talhaoui N, Taamalli A, Gómez-Caravaca AM, et al. Phenolic compounds in olive leaves: analytical determination, biotic and abiotic influence, and health benefits. Food Res Intern 2015;77:92-108.

18. Uyla冈er V, Yildiz G. The historical development and nutritional importance of olive and olive oil constituted an important part of the mediterranean diet. Crit Rev Food Sci Nutr 2014;54:1092-101.

19. Romero C, Brenes M, Yousfi K, et al. Effect of cultivar and processing method on the contents of polyphenols in table olives. J Agric Food Chem 2004;52:479-84.

20. Marsilio V, Campestre C, Lanza B. Phenolic compounds change during California-style ripe olive processing. Food Chem 2001;74:55-60.

21. Del Caro A, Azara E, Delogu G, et al. Oligomeric anthocyanin formation in black table olives during anaerobic processing. Eur Food Res Technol 2006,223:749-54.

22. Charoenprasert S, Mitchell A. Factors influencing phenolic compounds in table olives (Olea europaea). J Agric Food Chem 2012;60:7081-95.

23. Owen RW, Haubner $R$, Würtele $G$, et al. Olives and olive oil in cancer prevention. Eur J Cancer Prev 2004,13:319-26.
24. Granados-Principal S, Quiles JL, Ramirez-Tortosa CL, et al. Hydroxytyrosol: from laboratory investigations to future clinical trials. Nutr Rev 2010,68:191-206.

25. Vinha AF, Ferreres F, Silva BM, et al. Phenolic profiles of Portuguese olive fruits (Olea europaea L.): influences of cultivar and geographical origin. Food Chem 2005,89:561-8.

26. Sivakumar G, Briccoli Bati C, Uccella N. HPLC-MS screening of the antioxidant profile of italian olive cultivars. Chem Nat Comp 2005;41:588-91.

27. Pérez-Cano FJ, Castell M. Flavonoids, inflammation and immune system. Nutrients 2016;8:659-62.

28 Gómez-Rico A, Fregapane G, Desamparados Salvador M. Effect of cultivar and ripening on minor components in Spanish olive fruits and their corresponding virgin olive oils. Food Res Intern 2008;41:433-40.

29. Damak N, Bouaziz M, Ayadi M, et al. Effect of the maturation process on the phenolic fractions, fatty acids, and antioxidant activity of the Chétoui olive fruit cultivar. J Agric Food Chem 2008;56:1560-6.

30. Cardoso SM, Guyot S, Marnet N, et al. Identification of oleuropein oligomers in olive pulp and pomace. J Sci Food Agric 2006;86:1495-502.

31. Fu S, Arráez-Román D, Menéndez JA, et al. Characterization of isomers of oleuropein aglycon in olive oils by rapid-resolution liquid chromatography coupled with electrospray time-of-flight and ion trap tandem mass spectrometry. Rapid Commun Mass Spectrom 2009,23:51-9.

32. Fu S, Segura-Carretero A, Arráez-Román D, et al. Tentative characterization of novel phenolic compounds in extra virgin olive oils by rapid resolution liquid chromatography coupled with mass spectrometry. J Agric Food Chem 2009;57:11140-7.

33. Boss A, Bishop KS, Marlow G, et al. Evidence to support the anticancer effect of olive leaf extract and future directions. Nutrients 2016;8:513-34.

34. Kontogianni VG, Charisiadis $P$, Margianni E, et al. Olive leaf extracts are a natural source of advanced glycation end product inhibitors. J Med Food 2013;16:817-22.

35 Pereira AP, Ferreira ICFR, Marcelino F, et al. Phenolic compounds and antimicrobial activity of olive (Olea europaea L. Cv. Cobrançosa) leaves. Molecules 2007;12:1153-62.

36. Mert C, Barut E, Ipek A. Quantitative seasonal changes in the leaf phenolic content related to the alternate-bearing patterns of olive (Olea europaea L. cv. Gemlik). J Agr Sci Tech 2013;15:995-1006.

37. Kiritsakis $K$, Kontominas $M G$, Kontogiorgis $C$, et al. Composition and antioxidant activity of olive leaf extracts from Greek olive cultivars. J Am Oil Chem Soc 2010,87:369-76.

38 Laguerre M, López Giraldo LJ, Piombo G, et al. Characterization of olive-leaf phenolics by esims and evaluation of their antioxidant capacities by the CAT assay. J Am Oil Chem Soc 2009;86:1215-25.

39. Katz JJ, Norris JR, Shipman LL, et al. Chlorophyll function in the photosynthetic reaction center. Annu Rev Biophys Bioeng 1978:7:393-434.

40. Minguez-Mosquera MI, Garrido-Fernindez J. Chlorophyll and carotenoid presence in olive fruit (Olea europaea). J Agric Food Chem 1989;37:1-7.

41. Brahmi F, Mechri B, Dabbou S, et al. The efficacy of phenolics compounds with different polarities as antioxidants from olive leaves depending on seasonal variations. Ind Crops Prod 2012;38:146-52.

42. Servili M, Esposto $S$, Fabiani R, et al. Phenolic compounds in olive oil: antioxidant, health and organoleptic activities according to their chemical structure. Inflammopharmacology 2009;17:76-84.

43. García-Martínez O, De Luna-Bertos E, Ramos-Torrecillas J, et al. Phenolic compounds in extra virgin olive oil stimulate human osteoblastic cell proliferation. PloS ONE 2016;11:e0150045. 
44. Owen RW, Mier W, Giacosa A, et al. Phenolic compounds and squalene in olive oils: the concentration and antioxidant potential of total phenols, simple phenols, secoroids, lignans and squalene. Food Chem Toxicol 2000;38:647-59.

45. Karkoula E, Skantzari A, Melliou E, Magiatis P. Direct measurement of oleocanthal and oleacein levels in olive oil by quantitative (1)H NMR. Establishment of a new index for the characterization of extra virgin olive oils. J Agric Food Chem 2012;60:11696-703.

46. Davin BD, Bedgar DL, Katayama T, Lewis NG. On the stereoselective synthesis of (1)-pinoresinol in Forsythia suspensa from its achiral precursor, coniferyl alcohol. Phytochem 1992;31:3869-74.

47. Tsukamoto H, Hisada S, Nishibe S. Lignans from Bark of the Olea plants. Chem Pharm Bull 1984;32:2730-5.

48. Brenes M, Hidalgo FJ, García A, et al. Pinoresinol and 1-acetoxypinoresinol, two new phenolic compounds identified in olive oil. J Am Oil Chem Soc 2000;77:715-20.

49. Owen RW, Mier W, Giacosa A, et al. identification of lignans as major components in the phenolic fraction of olive oil. Clin Chem 2000;46:976-88.

50. Montedoro G, Servili M, Baldioli M, Miniati E. Simple and hydrolyzable phenolic compounds in virgin olive oil. 1. their extraction, separation, and quantitative and semiquantitative evaluation by HPLC. J Agric Food Chem 1992;40:1571-6.

51 Andrewes P, Busch JL, De Joode T, et al. Sensory properties of virgin olive oil polyphenols: identification of deacetoxy-ligstroside aglycon as a key contributor to pungency. J Agric Food Chem 2003;51:1415-20.

52. Beauchamp GK, Keast RSJ, Morel D, et al. Phytochemistry: ibuprofen-like activity in extra-virgin olive oil. Nature 2005;437:45-6.

53. Iacono A, Gómez $R$, Sperry J, et al. Effect of oleocanthal and its derivatives on inflammatory response induced by lipopolysaccharide in a murine chondrocyte cell line. Arthrit Rheum 2010;62:1675-82.

54. Paiva-Martins F, Fernandes $J$, Rocha $S$, et al. Effects of olive oil polyphenols on erythrocyte oxidative damage. Mol Nutr Food Res 2009,53:609-16.

55. Psomiadou E, Tsimidou M. Simultaneous HPLC determination of tocopherols, carotenoids, and chlorophylls for monitoring their effect on virgin olive oil oxidation. J Agric Food Chem 1998,46:5132-8.

56. Mulinacci N, Romani A, Galardi $C$, et al. Polyphenolic content in olive oil waste waters and related olive samples. J Agric Food Chem 2001;49:3509-14.

57. Rubio-Senent F, Martos S, Lama-Muñoz A, et al. Isolation and identification of minor secoiridoids and phenolic components from thermally treated olive oil by-products. Food Chem 2015;187:166-73.

58. Frankel E, Bakhouche A, Lozano-Sánchez J, et al. Literature review on production process to obtain extra virgin olive oil enriched in bioactive compounds. Potential use of byproducts as alternative sources of polyphenols. J Agric Food Chem 2013;61:5179-88.

59. Ghanbari R, Anwar F, Alkharfy KM, et al. Valuable nutrients and functional bioactives in different parts of olive (Olea europaea L.). A review. Int J Mol Sci 2012;13:3291-340.

60. Servili M, Baldioli M, Selvaggini R, et al. High-performance liquid chromatography evaluation of phenols in olive fruit, virgin olive oil, vegetation waters, and pomace and $1 D$ - and $2 D$-nuclear magnetic resonance characterization. J Am Oil Chem Soc 1999;76:873-82.

61. Artajo LS, Romero MP, Motilva MJ. Transfer of phenolic compounds during olive oil extraction in relation to ripening stage of the fruit. J Sci Food Agric 2006;86:518-27.

62. Goldsmith CD, Stathopoulos CE, Golding JB, Roach PD. Fate of the phenolic compounds during olive oil production with the traditional press method. Intern Food Res J 2014;21:101-9.

63. Leouifoudi I, Zyad A, Amechrouq A, et al. Identification and characterisation of phenolic compounds extracted from Moroccan olive mill wastewater. Food Sci Technol 2014,34:249-57.

64. Cioffi G, Pesca MS, De Caprariis MS, et al. Phenolic compounds in olive oil and olive pomace from Cilento (Campania, Italy) and their antioxidant activity. Food Chem 2010;121:105-11.

65. Cicerale S, Conlan XA, Barnett NW, Keast RSJ. The concentration of oleocanthal in olive oil waste. Nat Prod Res 2011;25:542-8.

66. Huang D, Ou B, Prior RL. The chemistry behind antioxidant capacity assays. J Agric Food Chem 2005;53:1841-56.

67. Boligon AA, Machado MM, Athayde ML. Technical evaluation of antioxidant activity. Med Chem 2014,4:517-22.

68. Singleton VL, Rossi JA. Colorimetry of total phenolics with phosphomolybdic-phosphotungstic acid reagents. Am J Enol Viticul 1965;16:144-58.

69. Giao MS, Gonzalez-Sanjose ML, Rivero-Perez MD, et al. Infusions of Portuguese medicinal plants: dependence of final antioxidant capacity and phenolic content on extraction features. J Sci Food Agric 2007;87:2638-47.

70. Samaniego Sánchez C, Troncoso González AM, García-Parrilla MC, et al. Different radical scavenging tests in virgin olive oil and their relation to the total phenol content. Anal Chim Acta 2007;593:103-7.

71. Gutfinger T. Polyphenols in olive oils. J Am Oil Chem Soc 1981;58:966-8.

72. Cetinkaya H, Koc M, Kulak M. Monitoring of mineral and polyphenol content in olive leaves under drought conditions: application chemometric techniques. Ind Crops Prod 2016;88:78-84.

73. Brahmi F, Mechri B, Dhibi M, Hammami M. Variations in phenolic compounds and antiradical scavenging activity of Olea europaea leaves and fruits extracts collected in two different seasons. Ind Crops Prod 2013;49:256-64. 